\title{
Microsatellite Markers from Peronospora tabacina, the Cause of Blue Mold of Tobacco, Reveal Species Origin, Population Structure, and High Gene Flow
}

\author{
Marcin Nowicki, ${ }^{1, \dagger}$ Denita Hadziabdic, ${ }_{1}^{1}$ Robert N. Trigiano, ${ }^{1}$ Fabian Runge, ${ }^{2,3}$ Marco Thines,${ }^{3,4}$ \\ Sarah L. Boggess, ${ }^{1}$ Jean Ristaino, ${ }^{5}$ and Otmar Spring ${ }^{2}$ \\ ${ }^{1}$ Department of Entomology and Plant Pathology, University of Tennessee, Knoxville 37996-4560, U.S.A. \\ ${ }^{2}$ Institute of Botany 210, University of Hohenheim, D-70593 Stuttgart, Germany \\ ${ }^{3}$ Biodiversity and Climate Research Centre, Senckenberg Gesellschaft für Naturforschung, D-60325 Frankfurt am Main, Germany \\ ${ }^{4}$ Department of Life Sciences, Institute of Ecology, Evolution and Diversity, Goethe University Frankfurt, D-60323 Frankfurt am Main, \\ Germany \\ ${ }^{5}$ Department of Entomology and Plant Pathology, Emerging Plant Disease and Global Food Security Cluster, North Carolina State University, \\ Raleigh 27650, U.S.A. \\ Accepted for publication 26 May 2021.
}

\begin{abstract}
Peronospora tabacina is an obligate parasite that causes blue mold of tobacco. The pathogen reproduces primarily by sporangia, whereas the sexual oospores are rarely observed. A collection of 122 isolates of $P$. tabacina was genotyped using nine microsatellites to assess the population structure of individuals from subpopulations collected from central, southern, and western Europe; the Middle East; Central America; North America; and Australia. Genetic variations among the six subpopulations accounted for $\sim 8 \%$ of the total variation, including moderate levels of genetic differentiation, high gene flow among these subpopulations, and a positive correlation between geographic and genetic distance $(r=0.225 ; P<0.001)$. Evidence of linkage disequilibrium $(P<0.001)$ showed that populations contained partially clonal subpopulations but that subpopulations from Australia and Mediterranean
\end{abstract}

ABSTRACT
Europe did not. High genetic variation and population structure among samples could be explained by continuous gene flow across continents via infected transplant exchange and/or long-distance dispersal of sporangia via wind currents. This study analyzed the most numerous $P$. tabacina collection and allowed conclusions regarding the migration, mutation, and evolutionary history of this obligate biotrophic oomycete. The evidence pointed to the species origin in Australia and identified intracontinental and intercontinental migration patterns of this important pathogen.

Keywords: clonal reproduction, evolution, genetic diversity, longdistance dispersal, obligate pathogen, oomycetes, Oomycota, population biology
Tobacco (Nicotiana tabacum L.) is grown throughout the world in 124 countries (http://tobaccoatlas.org/topic/growing/). There are a number of other species of wild and cultivated tobacco found on all continents except Antarctica. Despite the well-documented health risks of tobacco usage (Hackshaw et al. 2018; Patrick et al. 1994), tobacco continues to be an important cash crop of the agricultural economies of many countries, particularly in developing nations in Asia and Africa (http://tobaccoatlas.org/topic/growing/). Tobacco plants suffer from many diseases, including those caused by nematodes, fungi, and bacteria. Of particular concern are the fungus-like tobacco pathogens classified as the kingdom Stramenopiles and phylum Oomycota (Thines and Choi 2016). Among the disease-causing species in this phylum are the oomycetes classified as Peronosporaceae (Peronosporales), which includes Peronospora tabacina Adam (former synonym Peronospora hyoscyami f. sp. tabacina Skalicky).

${ }^{\dagger}$ Corresponding author: M. Nowicki; mnowicki@utk.edu

M. Nowicki, D. Hadziabdic-Guerry, and R. N. Trigiano are all first authors.

Funding: Funding was received from U.S. Department of Agriculture-Agricultural Research Service grant NACA 58-6062-6 to the laboratory of R. N. Trigiano.

*The $\boldsymbol{e}$-Xtra logo stands for "electronic extra" and indicates that one supplementary figure, supplementary materials, and supplementary tables are published online.

The author(s) declare no conflict of interest.

(c) (1) () () Copyright ( 92022 The Author(s). This is an open access article discc)
This downy mildew pathogen causes blue mold of cultivated tobacco and some wild Nicotiana species (Spring et al. 2018). For a more detailed review of this and related biotrophic oomycetes, readers should refer to Spring et al. (2018).

P. tabacina is a diploid, obligate biotrophic pathogen that produces primarily foliar lesions, but it may also incite systemic infections (Milholland et al. 1981). Primarily known in nursery transplant beds and periodic epidemics before 1979, a blue mold epidemic of field-grown plants in Jamaica and Cuba during the 1979 growing season spread to continental North America (Aylor et al. 1982). This caused an estimated $\$ 250$ million in damages to the crop in the United States (Lucas 1980). Since the initial reports in 1980, the pathogen has become established throughout the tobacco-growing regions of the world (Ristaino et al. 2007; Sukno et al. 2002), including Europe, where it causes regular epidemics and great economic losses. Control of the pathogen relies on fungicides, but isolates resistant to metalaxyl emerged in the early 1980s in the United States (Bruck et al. 1982) and later in Europe (Krauthausen et al. 2003; Zipper et al. 2009). In addition, the decreased efficacy of dimethomorph to control P. tabacina was reported in the northeastern United States (LaMondia 2009, 2013). Only one burley tobacco cultivar resistant to P. tabacina exists, and few resistant cultivars of flue-cured tobacco are currently undergoing development (Ristaino et al. 2007). Pathogen resistance can be found in some wild tobacco relatives, and efforts have been made to introgress a gene (RBMI) conferring complete resistance to $P$. tabacina from Nicotiana debneyi into $N$. tabacum (Wu et al. 2015). The region conferring $P$. tabacina resistance was mapped to a 3.3-cM fragment of tobacco chromosome 7 and suffered from 
linkage drag, which was also evidenced by the loss of Phytophthora nicotianae resistance (blackshank) (Dluge 2017; Wu et al. 2015).

$P$. tabacina exhibits primarily asexual or clonal reproduction via sporangia (also called conidia), but there have been few reports of its sexual reproduction by oospores embedded in the host tissues (LaMondia 2010; Milholland et al. 1981; Spurr and Todd 1982). Some indirect evidence suggested that $P$. tabacina may overwinter locally as oospores and initiate disease in the spring in the United States (Aylor et al. 1982; LaMondia 2010). In the field, the disease may also be incited by asymptomatic, infected transplants (Moss and Main 1988). Another hypothesis is that P. tabacina survives in the subtropical areas of North America (Texas, Caribbean) and South America, southern Europe, the Middle East, and northern Africa on populations of $N$. tabacum and other related Nicotiana species (Aylor et al. 1982; LaMondia 2009). The annual occurrence of the disease in the northern regions is initiated primarily by sporangia arriving via air currents (Aylor et al. 1982; Blanco-Meneses 2010; Ojiambo and Holmes 2011). Subsequent infections on the same plant in the same field or other fields are caused by the rapid colonization of the host and copious asexual sporulation of the pathogen (Aylor 1986). The pathogen is a prolific producer of spores, and it has been estimated that 500 ha of heavily diseased tobacco can produce $\sim 6.44 \times 10^{13}$ spores per day (Aylor 1986).

Because of the difficulty of working with an obligate pathogen and obtaining an adequate number of individual isolates, there is limited information regarding the population biology and genetics of $P$. tabacina. Only a few studies have aimed to characterize the genetic diversity of $P$. tabacina. A restriction fragment length polymorphism analysis of $P$. tabacina isolates from Kentucky and other regions in the United States indicated low diversity of the analyzed isolates (Sukno et al. 2002). Additionally, Zipper et al. (2009) used inter simple sequence repeats and found low genetic variability among P. tabacina collected in Germany. Blanco-Meneses (2010) analyzed multilocus sequences of several regions, including $\operatorname{cox} 2$, $y p t 1$, and Igs2, and described high genetic variability between isolates from Europe and North America.

Microsatellites (simple sequence repeats [SSRs]), often used in population genetics studies (Tautz 1989), have been developed for several downy mildew organisms, including $P$. tabacina (Kanetis et al. 2009; Trigiano et al. 2012). The genetic diversity of 44 isolates of P. tabacina from Europe, North America, South America, and the Middle East was evaluated using 10 SSRs developed from a German pathogen sample (Trigiano et al. 2012). Their results were similar to those of other primarily asexually reproducing downy mildew pathogens such as Pseudoperonospora cubensis (Kanetis et al. 2009) and Peronosclerospora sorghi (Perumal et al. 2008). In contrast, Plasmopara viticola, which reproduces both sexually and asexually, has been shown to have higher numbers of alleles among tested loci, and the majority of identified individuals are unique, nonclonal genotypes (Gobbin et al. 2003). Notably, next-generation sequencing has allowed for the drafting of the $P$. tabacina genome, completion of the mitogenome, examination of their structure and synteny with the genomes of related oomycetes, and assessment of richness in pathogenicity-related and effector genes (Derevnina et al. 2015).

In the present study, we used the published SSRs (Trigiano et al. 2012) to investigate the spatial structure and degree of gene flow among P. tabacina populations from Central America, North America, Europe, the Middle East, and Australia. We hypothesized that the global population of this pathogen is spatially structured and has varying levels of diversity across the regions. We also hypothesized that the variability detected using microsatellites will be sufficient to identify the tentative geographic origin of $P$. tabacina. The specific objectives were as follows: to estimate genetic diversity across distinct geographic populations; to evaluate whether $P$. tabacina populations are reproduced clonally; to determine whether populations of $P$. tabacina are geographically substructured; and to infer the migration patterns and the species demographic/evolutionary history.

\section{MATERIALS AND METHODS}

Isolates of $\boldsymbol{P}$. tabacina, microsatellite markers, and amplification conditions. A collection of 153 isolates of $P$. tabacina was used during this study (Supplementary Table ST1). Samples were obtained from North America, Central America, Europe, and Australia; they were collected from 1903 to 2016. The gDNA of herbarium and fresh samples from Australia, Europe, and the Middle East was extracted using the Analytikjena Plant Kit as previously described (Telle and Thines 2008). The gDNA from the current Central American and North American samples (Trigiano et al. 2012) was extracted from frozen sporangiophores using the CTAB extraction protocol (Doyle and Doyle 1987).

After the elimination of isolates that failed to amplify across at least five loci and clone correction, 122 unique $P$. tabacina multilocus genotypes (MLGs; Fig. 1) were grouped as subpopulations according to their geographical origin as follows: Australia (AUS), $n=9$ (collected from 1903 through 1972); Europe (EU), $n=74$ (collected from 1960 through 2016); and Central America and North America (NAM), $n=39$ (collected from 1945 through 2006). The latter two groups were also subdivided to gain more insights during independent analyses (Table 1; Supplementary Table ST1). EU was split into Germany and Poland (central Europe; EU_GP; $n=46$ ), southern Europe and the Middle East (EU_SEME; $n=10$ ), and western Europe (EU_WE; $n=18$ ). NAM was split into Central America and the southern United States (NAM_CAM; $n=16$ ) and the northeastern United States (NAM_NE; $n=23$ ).

The isolates were genotyped using 16 SSRs (Trigiano et al. 2012). However, data from seven SSRs were excluded from the analyses: four of these 16 SSRs were monomorphic and an additional three had a high percentage of missing and/or uninformative data. The details including sequences for seven of the nine retained primer pairs used in the study (PT004, PT007, PT014, PT028, PT032, PT047, and PT048) have been described by Trigiano et al. (2012). The remaining two primer pairs, PT034 (GenBank accession KX608619; F: CATACCAGGCCATATTTTGCAC; R: TGT TTTGACCCATACATTCGTG; Motif $=[\mathrm{AC}]_{12}$; expected size of allele $=124 \mathrm{bp})$ and PT041 (JF261119; F: TCCTTTCTATCCT CAAAATACAAGC; R: CAGACAAAGGATGAACAGATGG; Motif $=[\mathrm{CA}]_{36} \mathrm{CT}[\mathrm{CA}]_{36}$; expected size of allele $=280 \mathrm{bp}$ ) were also used to genotype the collection. Polymerase chain reaction (PCR) amplifications were performed in a $10-\mu l$ reaction mixture consisting of $4 \mathrm{ng}$ of gDNA, $1 \mu \mathrm{M}$ final concentration of each primer, $5 \mu \mathrm{l}$ of $2 \times$ AccuStart II (Quantabio, Beverly, MA), and $0.5 \mu \mathrm{l}$ of dimethyl sulfoxide (DMSO). To validate the data, the gDNA extracted from the original $P$. tabacina sample used for SSR development (PT862; Horkheim, Württemberg, Germany) (Supplementary Table ST1) was used as positive control, and sterile distilled water was used as the nontemplate control. Amplification conditions followed a touchdown temperature protocol (Korbie and Mattick 2008) described by Trigiano et al. (2012) and were used for all tested SSRs. The following thermal profile was used throughout: $94^{\circ} \mathrm{C}$ for $3 \mathrm{~min}, 15$ cycles of $94^{\circ} \mathrm{C}$ for $40 \mathrm{~s}, 40 \mathrm{~s}$ initially at $63^{\circ} \mathrm{C}$ and subsequently decreasing $0.5^{\circ} \mathrm{C}$ per cycle, and $72^{\circ} \mathrm{C}$ for $30 \mathrm{~s}$. The next 20 cycles consisted of $94^{\circ} \mathrm{C}$ for $40 \mathrm{~s}, 55^{\circ} \mathrm{C}$ for $40 \mathrm{~s}$, and $72^{\circ} \mathrm{C}$ for $30 \mathrm{~s}$, ending with $72^{\circ} \mathrm{C}$ for $4 \mathrm{~min}$. Amplification products (alleles) were separated, visualized, and sized using the QIAxcel Capillary Electrophoresis System (Qiagen, Valencia, California) as described previously (Dean et al. 2013; Trigiano et al. 2012) using the internal 15/600-bp alignment marker and 25- to 500-bp size marker. Samples that amplified erratically (more than four missing loci) after three reruns were discarded from further analyses; any loci that failed to amplify but were retained at that stage were deemed missing data.

Population genetics analyses. Diversity indices. Raw allele lengths were converted to allelic classes using the TANDEM version 
1.09 program (Matschiner and Salzburger 2009). TANDEM identifies the best binning parameter for rounding the allele sizes to valid integers using a simple algorithm coded in Ruby. The program calculates the average rounding error and indicates the reliability and quality of the binned dataset. On finding the best fit values given the repeat motif size, allele sizes are replaced with their rounded equivalents and a graphical output file with summary statistics is generated. The binned dataset was transformed to the repeat number using the repeated motif size information ( 2 bp for all nine SSRs used in this study) for all subsequent analyses. All analyses were performed for the three subpopulations dataset of $P$. tabacina (AUS, EU, NAM) and then independently for the six subpopulations dataset (AUS, EU_GP, EU_SEME, EU_WE, NAM_CAM, NAM_NE). No clonal
MLGs were detected; therefore, all subsequent analyses of $P$. tabacina populations were performed using the dataset of 122 diploid individuals across nine SSRs.

SPAGeDI version 1.5d (Hardy and Vekemans 2002, 2015) was used to calculate the population-wise and locus-wise indices of genetic diversity indices, including Nei's gene diversity (heterozygosity expected under Hardy-Weinberg assumptions, standardized for the sample size; $H_{E}$ ) (Nei 1978), observed heterozygosity $\left(H_{O}\right)$, MLG counts, and allelic richness with rarefaction $\left(A_{R}\right)$, and to assess the presence of phylogeographic signals among and within the P. tabacina subpopulations (Hardy and Vekemans 2015) by permutation of the allele sizes among alleles within loci. GenAlEx version 6.503 (Peakall and Smouse 2012), an MS Excel macro,

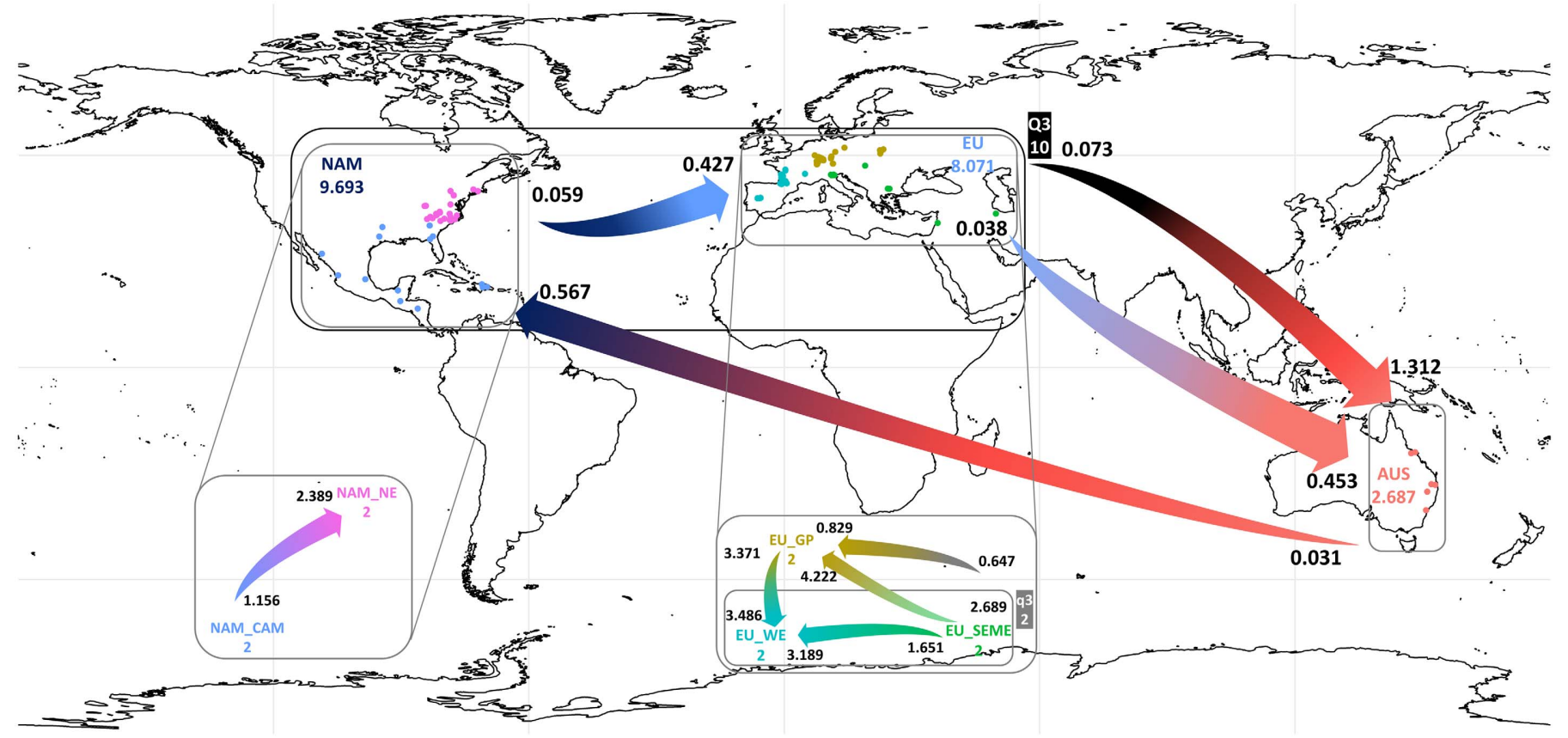

Fig. 1. Geographic origins of the Peronospora tabacina collection, grouping by geography, and results of isolation with migration (IMa3) analysis. The data illustrate the gene flow among the sampled populations of $P$. tabacina in Europe, America, and Australia. Effective population sizes $(q=4 \times N \times \mu)$ are indicated in the same colors as the population abbreviations. Migration arrows indicate estimated $2 \mathrm{Nm}$ values from one population to another over the time interval when both populations exist. Population sizes are scaled by the geometric mean of the mutation rates of the loci used for the analysis. Boxes delimit the subpopulations and their phylogenetic grouping as inferred by IMa3. Population abbreviations are as follows: AUS, Australia; EU, Europe; NAM, Central and North America; Q3, undifferentiated EU and NAM. The latter two groups were also subdivided to gain more insight regarding the independent analyses; EU was split into Germany and Poland (Central Europe; EU_GP), southern Europe and the Middle East (EU_SEME), western Europe (EU_WE), and undifferentiated EU_WE and EU_SEME (q3). NAM was split into southern North America (NAM_CAM) and northeastern United States (NAM_NE).

TABLE 1. Populationwise diversity indices across the clone-corrected data of 122 Peronospora tabacina multilocus genotypes using nine microsatellite loci ${ }^{\mathrm{a}}$

\begin{tabular}{|c|c|c|c|c|c|c|c|c|c|c|c|c|}
\hline Population & $n$ & $\%$ amp & $N_{A}$ & $N_{A E}$ & $A_{R}$ & $P_{A}$ & $H_{E}$ & $H_{O}$ & $F_{I}$ & $H$ & $\lambda$ & $\bar{r}_{d}$ \\
\hline \multicolumn{13}{|c|}{ Three subpopulations } \\
\hline AUS & 9 & 88.9 & 4.56 & 3.80 & 4.20 & 5 & 0.68 & 0.39 & $0.44^{\mathrm{b}}$ & 2.2 & 0.89 & $0.06 \mathrm{~ns}$ \\
\hline EU & 74 & 94.6 & 8.67 & 4.52 & 4.87 & 16 & 0.74 & 0.57 & $0.24^{\mathrm{b}}$ & 4.3 & 0.99 & $0.14^{\mathrm{b}}$ \\
\hline Overall & 122 & 94.2 & 12.22 & 5.58 & 5.56 & $\mathrm{n} / \mathrm{a}$ & 0.80 & 0.58 & $0.27^{\mathrm{b}}$ & 4.8 & 0.99 & $0.12^{\mathrm{b}}$ \\
\hline \multicolumn{13}{|c|}{ Six subpopulations } \\
\hline AUS & 9 & 88.9 & 4.56 & 3.80 & 4.20 & 5 & 0.68 & 0.39 & $0.44^{\mathrm{b}}$ & 2.2 & 0.89 & $0.06 \mathrm{~ns}$ \\
\hline EU_GP & 46 & 95.7 & 8.00 & 4.24 & 4.69 & 6 & 0.73 & 0.57 & $0.22^{\mathrm{b}}$ & 3.8 & 0.98 & $0.17^{\mathrm{b}}$ \\
\hline NAM_CAM & 16 & 93.7 & 8.00 & 6.63 & 5.92 & 19 & 0.81 & 0.65 & $0.21^{\mathrm{b}}$ & 2.8 & 0.94 & $0.20^{\mathrm{b}}$ \\
\hline NAM NE & 23 & 98.9 & 6.89 & 4.34 & 4.80 & 3 & 0.72 & 0.64 & $0.12^{\mathrm{c}}$ & 3.1 & 0.96 & $0.10^{\mathrm{b}}$ \\
\hline Overall & 122 & 92.9 & 12.22 & 5.58 & 5.56 & $\mathrm{n} / \mathrm{a}$ & 0.80 & 0.58 & $0.27^{\mathrm{b}}$ & 4.8 & 0.99 & $0.12^{\mathrm{b}}$ \\
\hline
\end{tabular}

${ }^{\mathrm{a}}$ Number of samples $(n)$, percentage of amplified samples (\%amp), number of alleles $\left(N_{A}\right)$, number of effective alleles $\left(N_{A E}\right)$, allelic richness rarefied $\left(A_{R}\right)$, private alleles $\left(P_{A}\right)$, unbiased expected heterozygosity (gene diversity; $\left.H_{E}\right)$, observed heterozygosity $\left(H_{O}\right)$, homozygosity excess (deficiency if negative; $\left.F_{I}\right)$, Shannon-Wiener Index of multilocus genotype diversity $(H)$, Simpson's Index $(\lambda)$, and standardized index of association $\left(\bar{r}_{d}\right)$ are shown. AUS, Australia; ns, not significant $(P>0.05)$; EU, Europe; NAM, Central and North America; n/a, not applicable; EU_GP, Germany and Poland in Central Europe; EU_SEME, southern Europe and the Middle East; EU_WE, western Europe; NAM_CAM, southern North America; NAM_NE, northeast United States.

${ }^{\mathrm{b}} P<0.001$.

${ }^{\mathrm{c}} P<0.01$. 
was used to identify the private alleles and to estimate the geneflow $\left(N_{m}\right)$. Poppr version 2.8.3 (Kamvar et al. 2014), a statistical package implemented in R 3.6.1 (R Core Team 2019), was used to calculate the index of association to assess the prevalent mode of reproduction (Agapow and Burt 2001; Brown et al. 1980). The standardized index of associations $\left(\bar{r}_{d}\right)$, unlike $I_{A}$, is independent of the sample size and number of loci, thus permitting comparisons among unequal subpopulations. However, both analyses produce the same $P$ values because they are monotonically related across the performed randomizations (Agapow and Burt 2001). The process included an analysis of a single representative for each MLG in a population, thereby recognizing that in asexually reproducing populations, the amplification of clones is caused by nonrandom mating (Milgroom 1996). In clonally reproducing populations, alleles are not inherited independently from generation to generation; therefore, assumptions of panmixia and Hardy-Weinberg equilibrium are violated. Poppr was also used to calculate genotype diversity G (Stoddart and Taylor 1988) and distribution (evenness; E.5) (Grünwald et al. 2003) and population differentiation index Dest (Jost 2008; Jost et al. 2018), and to reticulate the matrices of pairwise population distances (Nei 1972, 1978; Prevosti 1974). Hierarchical structuring was analyzed using an analysis of molecular variance (AMOVA) implemented in package ade4 version 7_1.7-13 (Dray and Dufour 2007) in R with 999 permutations of the dataset.

Population structure. $\mathrm{R}$ packages MASS version 7.3-51.4 (Ripley et al. 2013), ade4 (Dray and Dufour 2007), and vegan version 2.5-6 (Oksanen et al. 2013) were used to calculate the correlation of pairwise matrices of genetic and geographic distances among individuals (isolation-by-distance using Mantel's test). The tests were additionally standardized by the year of sampling (partial Mantel). The same software was used to calculate and plot the correlograms of Mantel's $r$ by the geographic distance class. The significance of the regression slope between the genetic and the logarithm of geographical distances was evaluated using Mantel tests with 1,000 permutations.

Discriminant Analysis of Principal Components (DAPC) implemented in adegenet version 2.1.1 (Jombart 2008) was used to explain structuring among $P$. tabacina subpopulations. Crosscheck and optimization were ensured by performing 100 analyses across principal components from 2 to 109 (number of total alleles in dataset -1). Alleles contributing the most to explaining the variance and used to project the dataset on a two-dimensional plane were identified using the same package.

The population structure of the $P$. tabacina genotyped dataset was analyzed using the Bayesian clustering implemented in STRUCTURE version 2.3.4 (Hubisz et al. 2009; Pritchard et al. 2000). Clusters were inferred using 30 independent Monte Carlo Markov Chains (MCMC) with 500,000 generations during the burnin period and 500,000 MCMC steps in the actual runs across the $\mathrm{K}$ (number of inferred clusters) values from 1 to 10. STRUCTURE results were visualized using PopHelper version 1.0.10 (Francis 2017), and the Evanno method (Evanno et al. 2005) was used to identify the most supported number of clusters. Subsequently, ObStruct version 1.0 (Gayevskiy et al. 2014) was used to assess how the population structure of the inferred ancestral profiles correlated to that of the preattributed populations. The program uses the ad hoc $R^{2}$ statistics whose values range from 0 (divergence of predefined populations or many migrations/admixtures among populations) to 1 (strong diversification and/or population structure) (Gayevskiy et al. 2014). Then, using independent steps, ObStruct removes each single preattributed or inferred population to allow insights regarding how it changes the $R^{2}$ statistics to identify groups with signals for the population structure.

Evolutionary scenario and demographic indices inferences. BOTTLENECK version 1.2.02 (Cornuet and Luikart 1996) was used to assess the presence of a bottleneck in the genotyped $P$. tabacina dataset. Both of the following mutation models applicable to the SSR data were used to analyze the $P$. tabacina bottlenecks or expansions: stepwise mutation model (SMM) and two-phase mutational model (TPM). Variance of the geometric distribution for TPM was set to 12 along with 95\% of SMM (Cornuet and Luikart, 1996). All three available statistical tests (sign, standard differences, and Wilcoxon) were used with 10,000 simulations to assess their significance. The shape of allele frequency distribution based on the collective results from those three tests (BOTTLENECK graph result) describes the status of the population, with a normal L-shaped graph indicating stable population and a mode-shift indicating a bottleneck in the evolutionary past (Cornuet and Luikart 1996).

Inferences on the evolutionary history of $P$. tabacina were performed using the approximate Bayesian computation DIYABC version 2.1 (Cornuet et al. 2014). During these analyses, the focus was on the putative geographic origin based on the collected samples of $P$. tabacina. The initial run focused on establishing limits of the input indices (population sizes, mutation rates) and used the whole dataset as one population, with the parameters stretched at least one order of magnitude beyond those defaulted by the program. The subsequent full DIYABC analysis was only performed using the precalculated $95 \%$ confidence interval $(95 \% \mathrm{CI})$ values for those indices and the three subpopulations dataset (AUS, EU, NAM) and phylogeny as deduced by IMa3. A detailed description of this analysis is provided in Supplementary Material File S1.

Isolation with migration analyses. Isolation with migration (IMa3) (Hey et al. 2018) was used to infer the demographics and the gene flow of our P. tabacina collection in Australia, Central America/North America, and Europe/the Middle East. Two North American subpopulations (NAM-CAM and NAM-NE) were analyzed during a separate group of runs. The three groups (AUS, EU, and NAM) as well as the three European subpopulations (EU_GP, EU_SEME, and EU_WE) were analyzed first for the bestsupported evolutionary scenario (feature available in IMa3); then, this scenario was included in the subsequent runs. The initial runs were performed to ensure reliability of the IMa3 parameters used with increased or decreased values of each of the critical indices (migration rate [ $m$; number of migrants per generation], effective population size $[q=4 \times N \times \mu]$, and time of split [ $t$; in mutations]) by a factor of five (Hey and Nielsen 2004). Those runs used the multiprocessor computation and at least 100 heated chains $(h a=$ 0.999 or 0.95 ). They also had an MCMC burn-in of $1,000,000$ steps and a proper run of 1,000,000 steps, and the results were saved every 100 steps. Results including the estimated sample sizes (only accepted when in thousands), swap rates $(>0.9$ for the first few heated chains, $\geq 0.1$ for the last heated chains), and the lack of trends exploring the probability space $(\log [P(G)+P(D \mid G)]$ graphs) were checked for reliability. After establishing the values of these three critical indices $(m, q$, and $t)$, five proper IMa3 runs were performed per dataset. The reliability of the results was assessed as described for the initial runs. The high-point values of such inferred indices $(m, q, t)$ resulting from the independent runs were checked for convergence across runs, and their averages were then plotted in R with ggplot 2 version 3.3.3 (Wickham 2011) along the approximate GPS coordinates of the isolates mapped using Google Earth version 7.3.2.5776.

\section{RESULTS}

Microsatellites and basic genetic diversity indices. Nine polymorphic SSRs used for genotyping of 122 isolates of $P$. tabacina revealed a total of 110 alleles with a range of 9 to 15 alleles per locus (Table 2). Our markers were robust in accruing the unique MLGs across the collection as indicated by the genotype accumulation curve, which is obtained by rarefaction and analogous to a species accumulation curve. Our results indicated that complete recognition (100\%) of all MLGs can be achieved with seven SSRs that were dispersed across the genome without major pairwise linkages among them (Supplementary Fig. S1A and C). The presence of private alleles (an allele found in only one population) was 
observed in all populations at both analyzed hierarchical levels (three or six subpopulations), with NAM subpopulation having the highest count $(n=23)$ and AUS having the lowest count $(n=5)$ (Table 1). The high overall allelic richness of 5.56 across nine loci was calculated by rarefaction to 12 alleles (PT004; AUS). In the six subpopulations dataset (with the subdivided EU and NAM), allelic richness had a high value of 5.92 calculated for NAM_CAM. Allelic richness is independent of sample size and can be used for comparisons among subpopulations. The high overall expected heterozygosity $\left(H_{E}=0.80\right)$ and distinctly lower observed heterozygosity $\left(H_{O}=0.58\right)$ suggested the existence of population structure for the $P$. tabacina dataset (Table 2). The NAM subpopulation (and NAM_CAM) had the highest values for both indices, whereas the AUS indicated the lowest diversity measures. Populations were highly differentiated from one another, as documented by high Dest values (Table 2), and substantial levels of gene flow were detected among the subpopulations $\left(N_{m}\right)$ (Table 2). Average to high deviations from Hardy-Weinberg expectations across all loci revealed an excess of heterozygotes $\left(F_{I}\right)$ (Table 1 ), and moderate to high levels of allele fixation were detected $\left(F_{S T}\right.$ analog: $R_{S T}$ ) (Table 2). $F_{S T}$ and $R_{S T}$ comparisons for detection of phylogeographic signals performed using SPAGeDI provided a slightly different result depending on the dataset subdivision. In the three subpopulations dataset (AUS, EU, and NAM), no phylogeographic signals were detected within or among subpopulations. Dataset subdivision into six subpopulations (AUS, EU_GP, EU_SEME, EU_WE, NAM_CAM, NAM_NE) allowed detection of the phylogeographic signal within subpopulations (but not among). These results implied the existence of the $P$. tabacina population substructure.

The hypothesis of random mating within $P$. tabacina subpopulations was tested using the standardized index of association $\bar{r}_{d}$, with 1,000 permutations of the genotyping dataset. Evidence of linkage disequilibrium (association between alleles; $\bar{r}_{d}=0.12 ; P<0.001$ ) (Table 1) indicated that $P$. tabacina populations contain partially clonal subpopulations. When we further tested the linkage disequilibrium across each of the three or six P. tabacina subpopulations, our results indicated sexual recombination in the AUS and EU_SEME groups only. In agreement with this observation, AUS had the fewest violations of Hardy-Weinberg equilibrium (Supplementary Fig. S1B).

The AMOVA analyses showed similar results for both subdivisions of the dataset with three and six subpopulations. The results congruently pointed to a low but significant part of the variance attributed at the subpopulation level $(\approx 10$ and $8 \%$, for three and six subpopulations, respectively) (Supplementary Table ST2). This result also suggested the existence of the population structure in our $P$. tabacina collection. A marginally greater score attributed to the among-subpopulations tier in the former dataset indicated intercontinental pathogen migration. At the same time, the majority of the variance remained at the individual samples level $(\approx 68$ and $71 \%$, for three and six subpopulations, respectively) (Supplementary Table ST2).

Population structure. The simplest model of genetic divergence, isolation by distance, was tested using the Mantel test. This analysis indicated that $\sim 5 \%$ of the $P$. tabacina variance was explained by the geographic spread of the pathogen $(r=0.229$; $r^{2}=0.052 ; P<0.001$ ) (Fig. 2A). Standardization by the year of sampling (partial Mantel test) improved that score marginally $\left(r^{\prime}=\right.$ $\left.0.244 ; r^{2}=0.059 ; P<0.001\right)$. The heat map plot of this analysis pointed to five possible "hot spots" of diversity (Fig. 2A). Moreover, the correlograms of Mantel r's indicated nonlinear changes in the index with increasing geographic distance, thus indicating patches of genetic (dis-)similarities (Fig. 2B).

Bayesian clustering of the $P$. tabacina dataset was analyzed with two subdivisions, the three and six preattributed subpopulations, with congruent results (Fig. 3). Both analyses indicated the existence of five genetically distinct clusters (Fig. 3A) with evidence of admixture (Fig. 3B and C). Analyses using ObStruct congruently pointed to divergence or intensive migration and admixture rather than long-standing population structure/diversification (Supplementary Table ST3). During the three subpopulations analysis, after sequentially removing the AUS and NAM subpopulations, only minor changes emerged that decreased the $R^{2}$ statistics. During the six subpopulations analysis, removal of the preattributed groups impacted the $R^{2}$ comparable with the removal of the inferred clusters; however, those impacts were smaller than those that occurred

TABLE 2. Locuswise estimates of genetic diversity parameters across the clone-corrected data of 122 Peronospora tabacina multilocus genotypes using nine microsatellite loci ${ }^{\mathrm{a}}$

\begin{tabular}{|c|c|c|c|c|c|c|c|c|c|c|c|}
\hline Population & $\%$ amp & Size (bp) & $N_{A}$ & $N_{A E}$ & $A_{R}$ & $H_{E}$ & $H_{O}$ & $N_{m}$ & Dest & $R_{I S}$ & $R_{S T}$ \\
\hline \multicolumn{12}{|c|}{ Three subpopulations } \\
\hline PT004 & 97.5 & $120-148$ & 14 & 5.77 & 5.82 & 0.83 & 0.89 & 2.36 & 0.47 & $0.22^{\mathrm{b}}$ & $0.12^{\mathrm{c}}$ \\
\hline PT007 & 89.3 & $180-228$ & 14 & 4.28 & 4.91 & 0.77 & 0.86 & 2.13 & 0.50 & $0.62^{\mathrm{d}}$ & $0.03^{\mathrm{b}}$ \\
\hline РT028 & 85.2 & $160-210$ & 11 & 3.38 & 4.42 & 0.70 & 0.03 & 1.93 & 0.65 & $0.85 \mathrm{~ns}$ & $0.27 \mathrm{~ns}$ \\
\hline PT032 & 95.1 & $160-188$ & 13 & 8.53 & 6.88 & 0.88 & 0.85 & 1.84 & 0.48 & $-0.17^{\mathrm{c}}$ & $0.02 \mathrm{~ns}$ \\
\hline PT034 & 98.4 & $108-130$ & 10 & 4.46 & 4.98 & 0.78 & 0.68 & 1.72 & 0.56 & $-0.08 \mathrm{~ns}$ & $0.17^{\mathrm{c}}$ \\
\hline PT041 & 93.4 & 80-102 & 12 & 9.35 & 7.11 & 0.89 & 0.91 & 2.70 & 0.55 & $-0.55 \mathrm{~ns}$ & $0.16 \mathrm{~ns}$ \\
\hline Overall & 94.2 & & 12.22 & 5.58 & 5.56 & 0.80 & 0.58 & $1.93 \pm 0.18$ & 0.45 & $0.10^{\mathrm{c}}$ & $0.12^{\mathrm{b}}$ \\
\hline \multicolumn{12}{|c|}{ Six subpopulations } \\
\hline PT004 & 97.5 & $120-148$ & 14 & 5.77 & 5.82 & 0.83 & 0.89 & 2.66 & 0.30 & $0.05 \mathrm{~ns}$ & $0.14^{\mathrm{c}}$ \\
\hline PT007 & 89.3 & $180-228$ & 14 & 4.28 & 4.91 & 0.77 & 0.86 & 2.50 & 0.27 & $0.18 \mathrm{~ns}$ & $0.14^{\mathrm{c}}$ \\
\hline PT014 & 94.3 & $156-186$ & 15 & 7.06 & 6.41 & 0.86 & 0.53 & 2.41 & 0.38 & $0.58^{\mathrm{b}}$ & $0.14^{\mathrm{b}}$ \\
\hline PT028 & 85.2 & $160-210$ & 11 & 3.38 & 4.42 & 0.70 & 0.03 & 2.06 & 0.24 & $-0.12 \mathrm{~ns}$ & $0.07^{\mathrm{b}}$ \\
\hline PT032 & 95.1 & $160-188$ & 13 & 8.53 & 6.88 & 0.88 & 0.85 & 2.03 & 0.50 & $0.84^{\mathrm{c}}$ & $0.27^{\mathrm{c}}$ \\
\hline
\end{tabular}

${ }^{a}$ Number of samples $(n)$, sizes of detected alleles (base pairs [bp]), number of alleles $\left(N_{A}\right)$, number of effective alleles $\left(N_{A E}\right)$, allelic richness rarefied $\left(A_{R}\right)$, private alleles $\left(P_{A}\right)$, unbiased expected heterozygosity (gene diversity; $\left.H_{E}\right)$, observed heterozygosity $\left(H_{O}\right)$, gene flow $(\mathrm{Nm})$, Jost's index of differentiation $($ Dest $)$, inbreeding coefficient $\left(R_{I S}\right)$, and allele fixation index $\left(R_{S T}\right)$ are shown. ns, not significant $(P>0.05)$.

b $P>0.01$.

${ }^{\mathrm{c}} P>0.001$.

${ }^{\mathrm{d}} P<0.05$. 
during the three subpopulations analysis. For the six subpopulations dataset, AUS had the strongest signal for population structure in the dataset, whereas NAM_CAM was the most diverse group. The impacts of the removal of the inferred clusters on $R^{2}$ was generally less pronounced during both analyses with the exception of the inferred genetic cluster hosting most of the AUS group (Supplementary Table ST3).

A multivariate analysis using DAPC separated the major three P. tabacina subpopulations (AUS, EU, NAM) but suggested migration and/or admixture within them (Fig. 4A). Within the EU or NAM subpopulations, substructure was not evidenced (Fig. 4B).

Evolutionary history and demographic indices inferences. Overall, there was no evidence for a $P$. tabacina bottleneck because subpopulations generally presented normal L-shaped distributions of
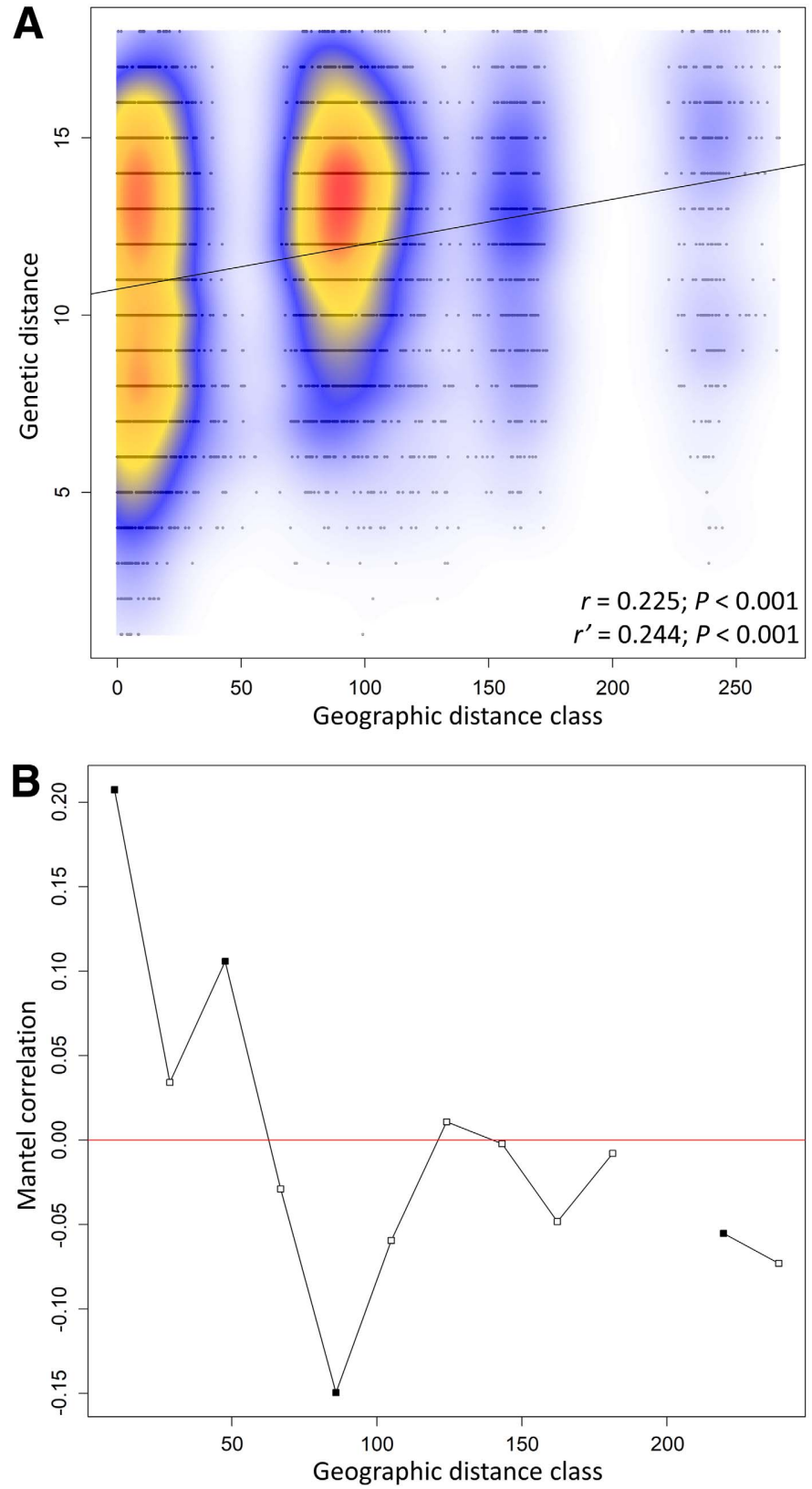

Fig. 2. Isolation by distance across the clone-corrected data of 122 Peronospora tabacina multilocus genotypes using nine microsatellite loci. A, Mantel $(r)$ and partial Mantel tests (standardized by year of sampling; $r^{\prime}$ ) comparing the matrices of genetic (vertical axis) and geographic (horizontal axis) distances. Significance was calculated based on 999 permutations. B, Mantel correlogram indicates the Mantel's $r$ for each given geographic distance class, with significant results $(P<0.05)$ marked with filled symbols. allele frequencies (Supplementary Table ST4). Individual tests pointed to some heterozygosity deficiencies, but the collective results from all three statistical tests only discovered an evolutionary bottleneck in $P$. tabacina for EU_SEME (Supplementary Table ST4). This indicated intensive gene flow among the subpopulations and was in agreement with the results of other analyses during this study.

The phylogenetic analyses (Prevosti distance; IMa3) suggested the AUS as the originating population. For evolutionary scenarios, we compared the following two scenarios: scenario 1 assumed AUS as the originating population, divergence through a "ghost" population, and separation into the EU and NAM populations; scenario 2 assumed AUS diverging from another "ghost" population but was otherwise identical to scenario 1. A DIYABC analysis supported scenario 1 rather than scenario 2 (Fig. 5A). During this evolutionary scenario, the original AUS population of $P$. tabacina split $\sim 9,380$ generations into the coalescent $\left(t_{2}\right)$, and an unsampled "ghost" subpopulation gave rise to EU and NAM 320 generations after its differentiation from AUS $\left(t_{1}\right)$. The originating AUS population was the smallest in size (effective population size: 14,200), and NAM was the largest $(42,400)$. The confidence of this scenario was drawn from the highest support for this scenario, good embedding of the observed genotyping dataset in the priors and $1 \%$ of the posterior pseudo-observed datasets (Fig. 5B), and smaller accuracy values for the estimates of posterior versus prior indices (bias and precision analysis of DIYABC). Additionally, the posterior predictive errors for scenario 1 and scenario 2 were 0.324 and 0.318 for the direct and logistic approaches, respectively, and the prior predictive errors were 0.403 and 0.409 , respectively (Supplementary File $\mathrm{S} 1$ ). The type I error estimates for scenario 1 and scenario 2 were 0.273 and 0.387 , respectively, for the direct and logistic approaches, whereas the type II error estimates were 0.583 and 0.464 , respectively. Our $P$. tabacina collection using the scenario 1 indicated a mutation rate of $\sim 3.24 \times 10^{-4}$ per locus per generation.

The relationships among the $P$. tabacina populations were also analyzed by reticulating the pairwise matrices of distances among the subpopulations in our collection using two dataset subdivisions: three subpopulations (AUS, EU, NAM) or six subpopulations (AUS, EU_GP, EU_SEME, EU_WE, NAM_CAM, NAM_NE), as in the other analyses (Fig. 6). Results of the dataset subdivided into three subpopulations indicated that the EU P. tabacina subpopulation is generally less distinct than other subpopulations (Fig. 6A). Using the dataset subdivided into six subpopulations, the AUS was considered the ancestral population with possible subsequent invasions into North America and Europe (Fig. 6B).

Isolation with migration. In addition to the global migration analysis (three subpopulations dataset: AUS, EU, NAM), intracontinental gene flow among populations of $P$. tabacina was evaluated during separate IMa3 analyses (Central America and North America, NAM_CAM, NAM_NE; Europe and the Middle East, EU_GP, EU_SEME, EU_WE). The initial 27 runs for global migration or within Europe (EU_GP, EU_SEME, EU_WE) performed to estimate input parameters $m, q$, and $t$ generated unreliable indices. Only after the addition of an unsampled "ghost" population did these two sets of runs show reliable chain mixing, exploration of the probability space, and sample sizes. The phylogenetic placement of the "ghost" population in those runs was assessed automatically by IMa3.

An analysis of the global migration patterns suggested the AUS population was the most ancestral among those sampled, but it indicated that the descendant $P$. tabacina (EU and NAM) served as the migration source, rather than sink, after pathogen establishment (Fig. 1). Also, migration from Central America and North America to Europe was estimated to be more than seven times higher than that in the opposite direction. Within Central America and North America, intensive migration from NAM_CAM (source) to NAM_NE (sink) was estimated to be twice the value in the opposite direction. This indicated that NAM_NE is an important inoculum sink for North America, with steady and intensive supply from NAM_CAM. In Europe and the Middle East, EU_GP was the first 


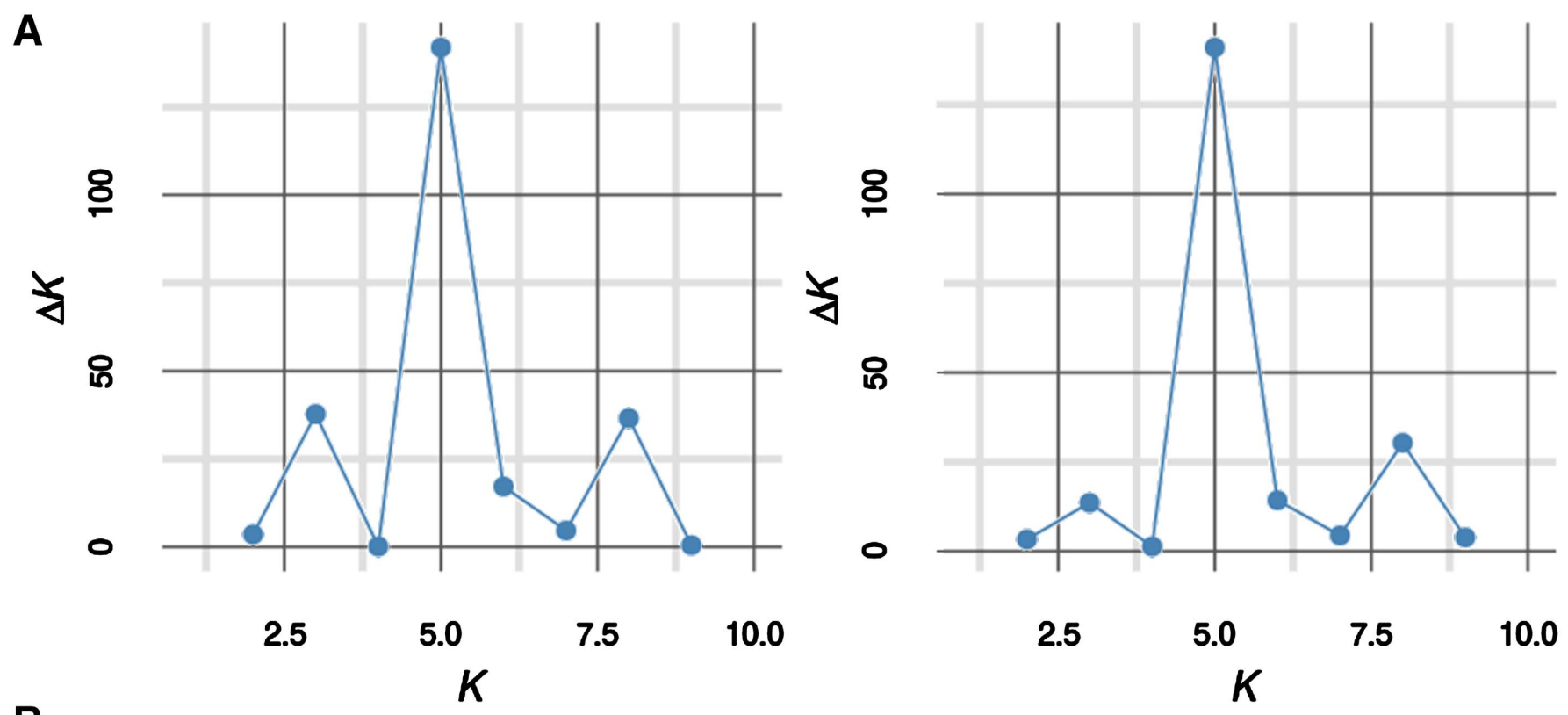

B

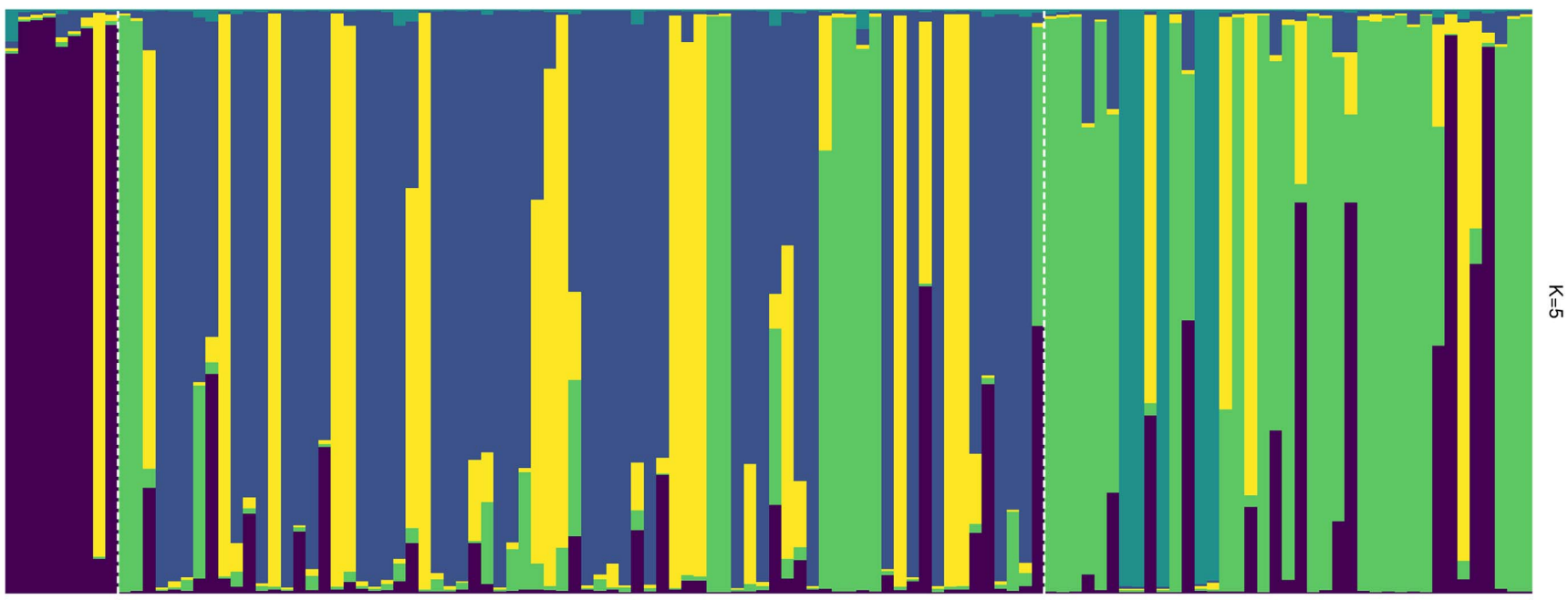

AUS

EU

NAM

C

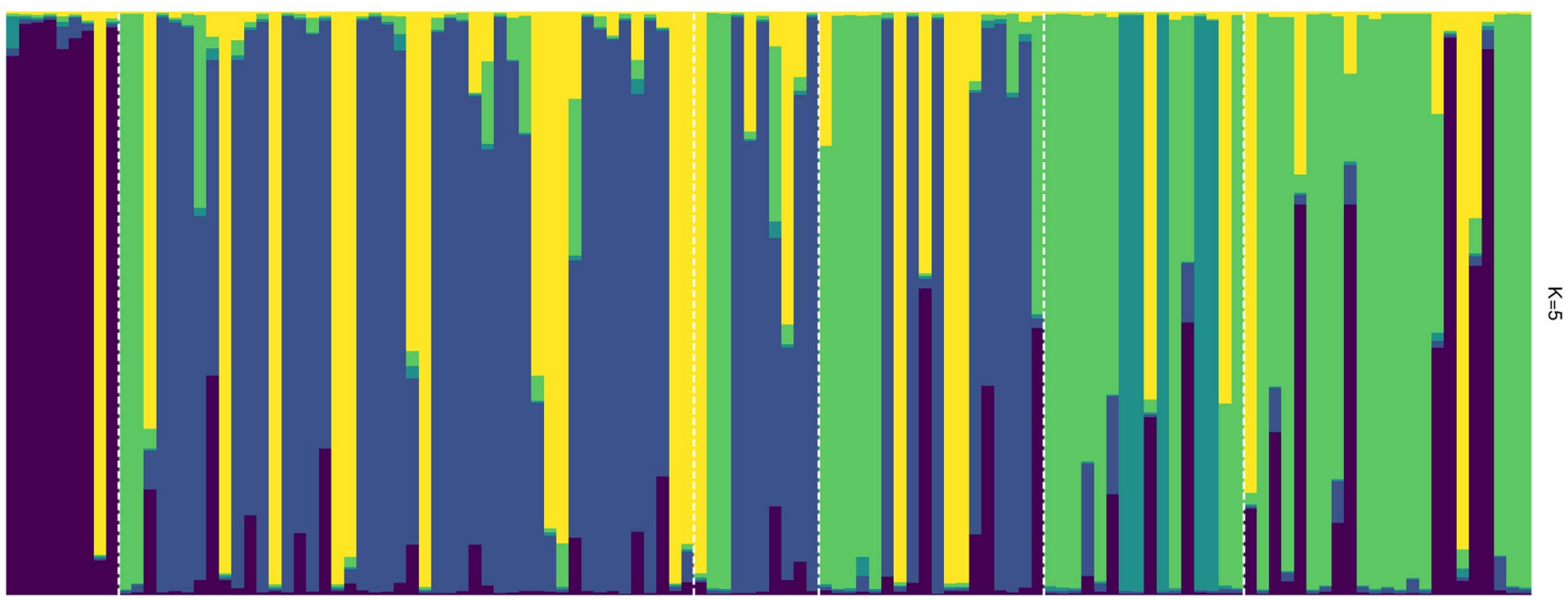

AUS

EU_GP

EU_SEME

EU_WE

Nam_CAM

Nam_NE

Fig. 3. Bayesian inference on population structure (STRUCTURE) of 122 Peronospora tabacina individuals. A, Evanno support for the number of genetically distinct clusters: (left) three subpopulations dataset and (right) six subpopulations dataset. STRUCTURE plot for B, three subpopulations (Australia [AUS], Europe [EU], and Central America and North America [NAM]) and C, six subpopulations (AUS, Germany and Poland in central Europe [EU_GP], southern Europe and the Middle East [EU_SEME], western Europe [EU_WE], southern North America [NAM_CAM], and northeast United States [NAM_NE]). The order of the individual samples was the same in B and C. 
differentiated population, and EU_WE was the sink population in Europe. Migration rates in Europe were very high and approximately twice the values calculated for Central America and North America (Fig. 1).

\section{DISCUSSION}

Our study of the population structure and genetic diversity among $P$. tabacina subpopulations using SSRs revealed high genetic diversity and gene flow among three continents and evidence of the population structure on global and continental scales. The evolutionary analyses pointed to AUS as the most ancestral and possibly the origin population of the species. This provides a potential solution to the previously voiced conundrum regarding the species origin alternatively located in Central America or North America, another origin of the Nicotiana genus (Blanco-Meneses 2010; Blanco-Meneses et al. 2018; Bourret et al. 2018; LaMondia and Aylor 2001). Analyses of our P. tabacina collection resulted in the acceptance of the hypothesis of the species population structure and intensive global migration.

Previous studies based on molecular markers other than SSRs found little genetic variability among the European and the North American populations of $P$. tabacina (Edreva et al. 1998; Sukno et al. 2002). In contrast, the nucleotide sequences from IGS2, yptl, and cox2 genes revealed high variability (Blanco-Meneses 2010; Blanco-Meneses et al. 2018). Moreover, their study provided evidence for long-distance migration patterns of the pathogen from the Central America to the northern United States as well as to Europe (Blanco-Meneses 2010; Blanco-Meneses et al. 2018). We found evidence of genetically heterogenous populations of $P$. tabacina using SSRs and similar migration patterns, thus indicating the extant genetic variability of this pathogen.

Lack of genetic stability and variation in P. tabacina isolates of the strains were found in Europe between 1978 and 1992 by a study (Edreva et al. 1998) that also indicated variability among populations based on the infected hosts, which could potentially trigger changes in gene expression of both the pathogen and the host plants. The authors further argued that the specificity underlying the relationship between host plants and obligate plant pathogens such as $P$. tabacina should be evaluated in the terms of pathogen-host coevolution (Edreva et al. 1998). Sukno et al. (2002) examined $P$. tabacina isolates from tobacco-growing regions in the United States and found similar patterns of low diversity and genetic stability of the strains. Furthermore, they found evidence of pairwise linkages for the markers used to genotype the United States populations of $P$. tabacina. One of the plausible explanations for low diversity found in their study was the fact that the pathogen does not overwinter in the Kentucky area, where many of the studied samples originated; therefore, it must be introduced from other tobacco-growing areas (Sukno et al. 2002).

The results of the earliest reports of $P$. tabacina were concurrent in the 1880s in distant parts of the world (Bailey 1890). In 1887, specimens that were considered a "destructive parasite on cultivated tobacco in Queensland ... were sent to Kew for determination" (Massee 1899). The same source identified the disease as "not uncommon on the leaves of Hanbane (Hyoscyamus niger)" in Europe (Massee 1899). The pathogen was already present on N. tabacum in the Azamgarh district in northwestern India in 1887 (Balfour 1887). In North America, its first occurrence was noted on the symptomatic $N$. glauca that escaped cultivation in the southwestern United States (California) (Farlow 1885). Therefore, the pathogen was considered endemic to two centers of origin, Australia and the Americas, and coincided with the origin of the host genus, Nicotiana spp. (Blanco-Meneses 2010; Blanco-Meneses et al. 2018; Bourret et al. 2018; LaMondia and Aylor 2001). An investigation of the available herbaria resources provided similar conclusion. The earliest available symptomatic samples were from Europe (1873: U.S. National Fungus Collection), North America (1885: U.S. National Fungus Collection), and Australia (1903: this study; 1905: U.S. National Fungus Collection). Although P. tabacina has been found in the 1934 herbarium samples of burley tobacco from Italy (Carrieri et al. 2017), the pathogen was not widespread in Europe
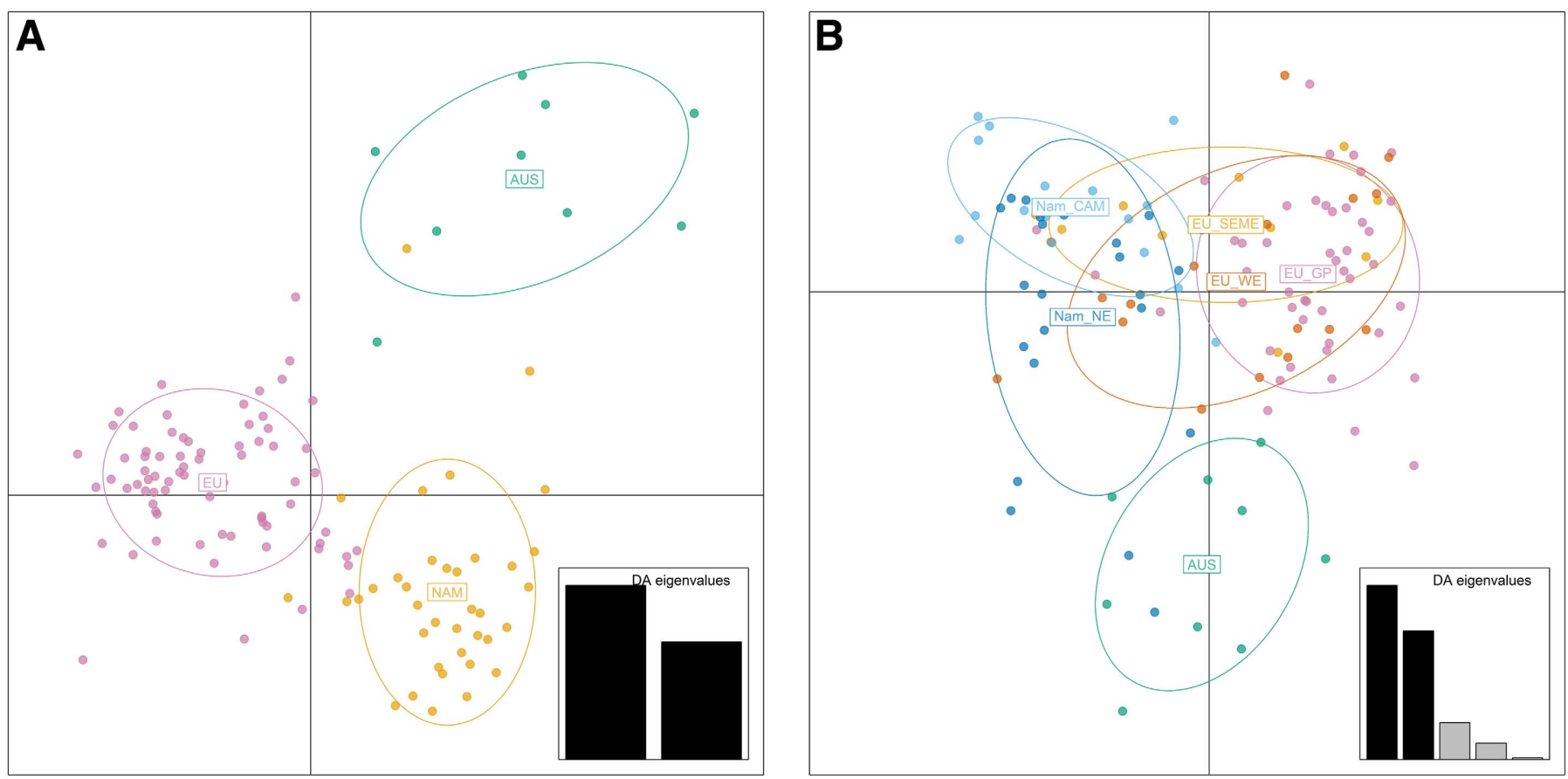

Fig. 4. Discriminant analysis (DA) of principal components across the clone-corrected data of 122 Peronospora tabacina multilocus genotypes using nine microsatellite loci. A, Dataset subdivision into three subpopulations (Australia [AUS], Europe [EU], and Central and North America [NAM]) and B, six subpopulations (AUS, Germany and Poland in Central Europe [EU_GP], southern Europe and the Middle East [EU_SEME], western Europe [EU_WE], southern North America [NAM_CAM], and northeast United States [NAM_NE]). The alleles that explain the most variance and their relative contributions are as follows: A, PT007.109 (8.26\%); PT047.100 (8.88\%); and B, PT028.88 (11.11\%); PT047.100 (2.65\%). Insets in bottom right in A and B show the screeplots of DA eigenvalues (n(pop) -1$)$. 
until the late 1950s and in the Middle East until the early 1960s. Moreover, our data supported the hypothesis that $P$. tabacina spread (Blanco-Meneses 2010) from central Europe (Germany, Poland) to western Europe and migrated from Mediterranean Europe and the Middle East to western Europe. Based on the evolutionary theory, an older source population would be the most genetically diverse compared with the recently colonized populations (Jorde et al. 1998). Although the population from Australia had the lowest diversity indices, it was also the smallest analyzed; however, it showed the fewest violations of Hardy-Weinberg equilibrium and signatures for sexual reproduction. Those features of $P$. tabacina from Australia and plausible rapid expansion in naïve Nicotiana spp. elsewhere allow for the acceptance of the tentative pathogen origin devised in this study. Because commercial tobacco farming in Australia decreased starting in the mid-1990s and no longer occurs, the only available sources of the pathogen are the historical samples and those collected from related species.

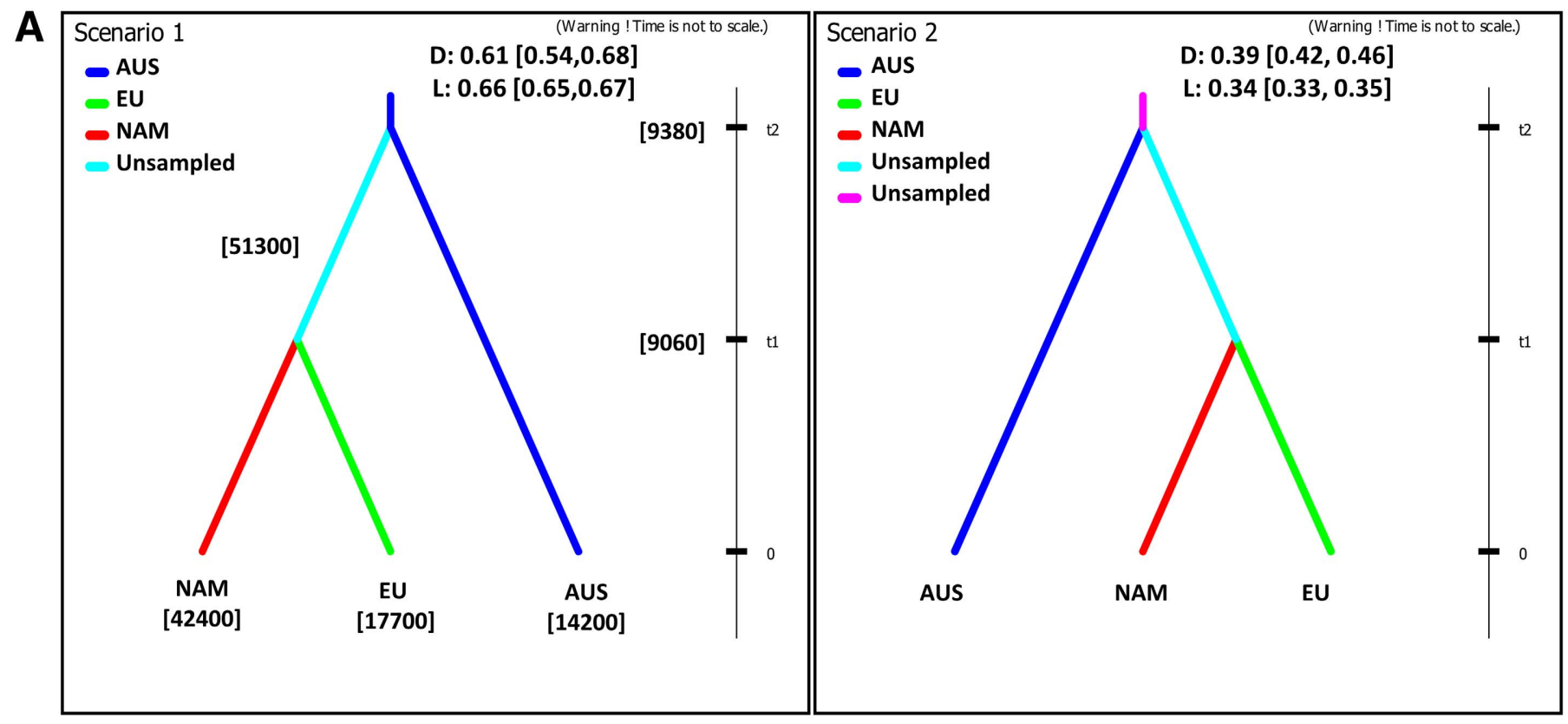

B

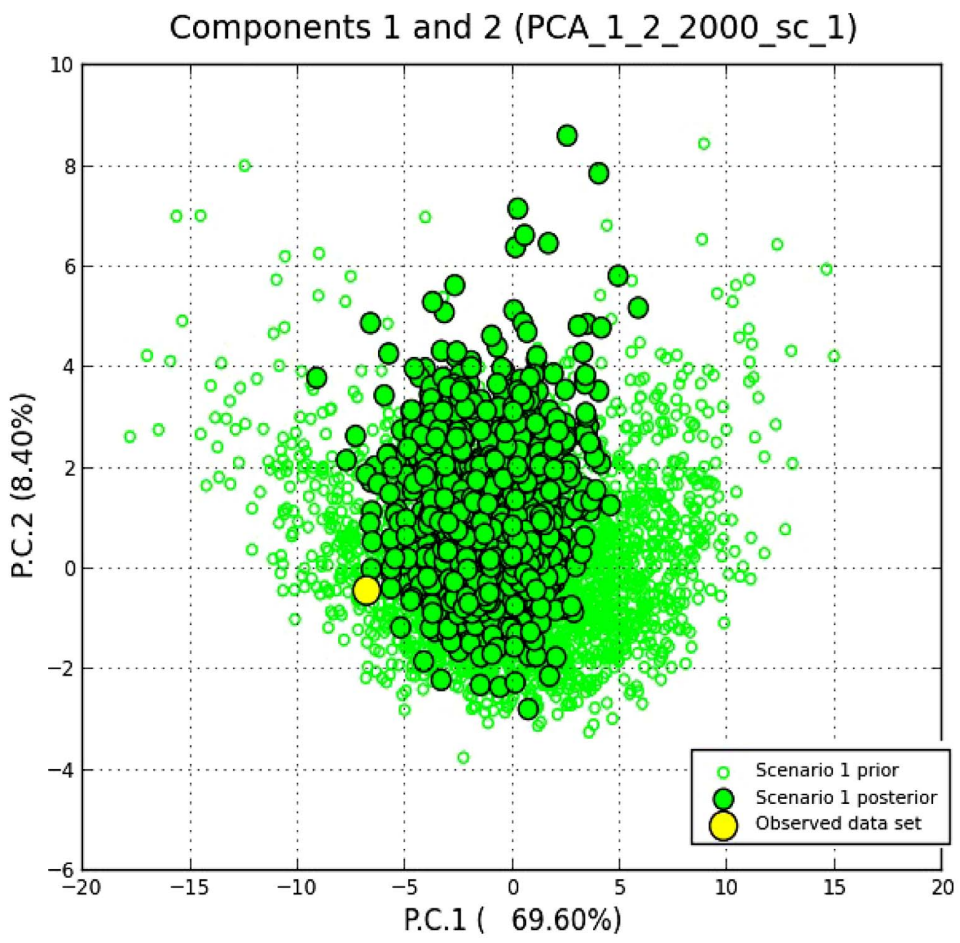

Fig. 5. Evolutionary scenarios by approximate Bayesian computation (DIYABC) of 122 Peronospora tabacina individuals. A, The best-supported evolutionary scenario (scenario 1; left) indicated that $P$. tabacina originated in Australia (AUS) and after rapid expansion of an unsampled population, gave rise to the populations in Europe (EU) and Central America and North America (NAM). The DIYABC analysis assessed the clone-corrected data of 122 P. tabacina multilocus genotypes using nine microsatellite loci. For either scenario, 1,000,000 pseudo-observed datasets (PODs) were generated using the prior indices ranges. The subsequent analyses utilized 1\% $(n=10,000)$ of the PODs closest to the observed dataset of $P$. tabacina within and among subpopulation indices. The comparative analyses of both scenarios provided support for each evolutionary scenario (D, direct; L, logistic; confidence intervals are given). Effective population sizes (shown in brackets). $\mathrm{t} n=$ time to split into parts (generations). B, Pseudo-observed datasets principal components (P.C.) analysis (1,000 priors and $1 \%$ of posteriors closest to the observed dataset plotted for reference). 
A careful investigation of the plant hosts affected by $P$. tabacina (Supplementary Table ST1; U.S. National Fungus Collection database) indicated that a range of native Solanaceae species can allow for its spread. Among the Nicotiana spp., the affected species included $N$. glauca, $N$. glutinosa, $N$. megalosiphon, $N$. repanda, and $N$. tabacum (Supplementary Table ST1) as well as $N$. alata, N. attenuata, $N$. benthamiana, $N$. bigelovii, $N$. caesia, $N$. gossei, $N$. longiflora, $N$. nesophila, $N$. rustica, $N$. stocktonii, $N$. suavolens, $N$. sylvestris, $N$. tomentosa, and $N$. trigonophyla (U.S. National Fungus Collection database). Many of those are native to Australia and show reactions compatible with $P$. tabacina (Hill and Mandryk 1962). Other related plants affected by $P$. tabacina include Atropa belladonna, Capsicum annuum, C. frutescens, Hyoscyamus niger, H. pusillus, and Solanum melongena (U.S. National Fungus Collection database). Only one specimen of symptomatic unrelated Indigofera spp. from Australia was found (Supplementary Table ST1). Because of this relatively broad host range, host jumps and pathogen expansion in newly introduced regions remain plausible scenarios typical of the pathogens from Peronosporales (Nowicki et al. 2021; Spring et al. 2013, 2018; Thines and Choi 2016). This bears particular importance considering that "Australian species on the whole were more resistant ... than the American species" of Nicotiana (Clayton and Gaine 1945; Hill and Mandryk 1962).

According to LaMondia and Aylor (2001), movement of the infected host tissues resulted in the first recorded $P$. tabacina infestations in Florida and Georgia (United States) in 1921. Intensive tobacco growth across Central America and North America resulting in many developed cultivars likely enabled the pathogen spread and evolution, thus establishing this part of world as an important source of $P$. tabacina. Our results using SSRs indicated such a pattern among populations of $P$. tabacina with the highest allelic richness observed in the subpopulations from Central America, North America, and western Europe. Genotypic diversity and genotype distribution across six subpopulations indicated similar trends, and the highest diversity was observed in those same subpopulations.

In a clonally reproducing system such as $P$. tabacina, $\mathrm{R}_{I S}$ was expected to be positive, indicating an excess of homozygotes relative to random mating (Halkett et al. 2005). In the recombining populations, $\bar{r}_{d}$ values are expected to be zero; however, in clonally reproducing organisms, these values are significantly different from zero. Our results provided evidence of linkage disequilibrium, indicating that the global $P$. tabacina population contains partially clonal subpopulations (association between alleles). Sukno et al. (2002) observed similar results, which confirmed that genetic recombination does not occur frequently among $P$. tabacina populations. Indirect proof of that fact includes the rare observations of oospores of P. tabacina in nature (Zipper et al. 2009), although we have no information regarding whether any samples in our collection showed such behavior.

Although the asexual cycle is the predominant form of reproduction for $P$. tabacina, sexually produced oospores embedded in host tissues have been reported (LaMondia 2010; Milholland et al. 1981; Spurr and Todd 1982). Detailed mechanisms of the genetic variation in the absence of sexual reproduction and the apparent homogeneity of nuclei in individual sporangia remain unknown, but this certainly does not preclude mutations or hyphal anastomosis from independent infections that create heterokaryosis (Tommerup 1989; Trigiano and Spurr 1987). The sexual phase of the life cycle remains poorly understood and its role in the disease cycle remains controversial. The pathogen is considered heterothallic, and compatible hyphae produce oogonia and antheridia that form thick-walled oospores that can endure harsh environmental conditions for up to 4 years (Blanco-Meneses 2010; LaMondia and Aylor 2001; Wolf et al. 1936). In comparison, related homothallic pathogen Pseudoperonospora cubensis shows considerable diversity (Nowicki et al. 2021), as does Discula destructiva, which is a fungus causing dogwood anthracnose that has no known sexual stage (Mantooth et al. 2017).

Pronounced genetic variation and evidence of the population structure based on DAPC and STRUCTURE analyses among the isolates of $P$. tabacina were noted in our study despite the continuous intracontinental and intercontinental gene flow. However, because of the obligate nature of this pathogen and differences in the sample sizes among subpopulations of $P$. tabacina in our study, further detailed studies are warranted. The results are quite intriguing because a large proportion of the $68-\mathrm{Mb} P$. tabacina genome is comprised of repetitive and transposon-like sequences (Derevnina et al. 2015; Sukno et al. 2002). With the high portion of the repetitive DNA found in $P$. tabacina and in other oomycetes
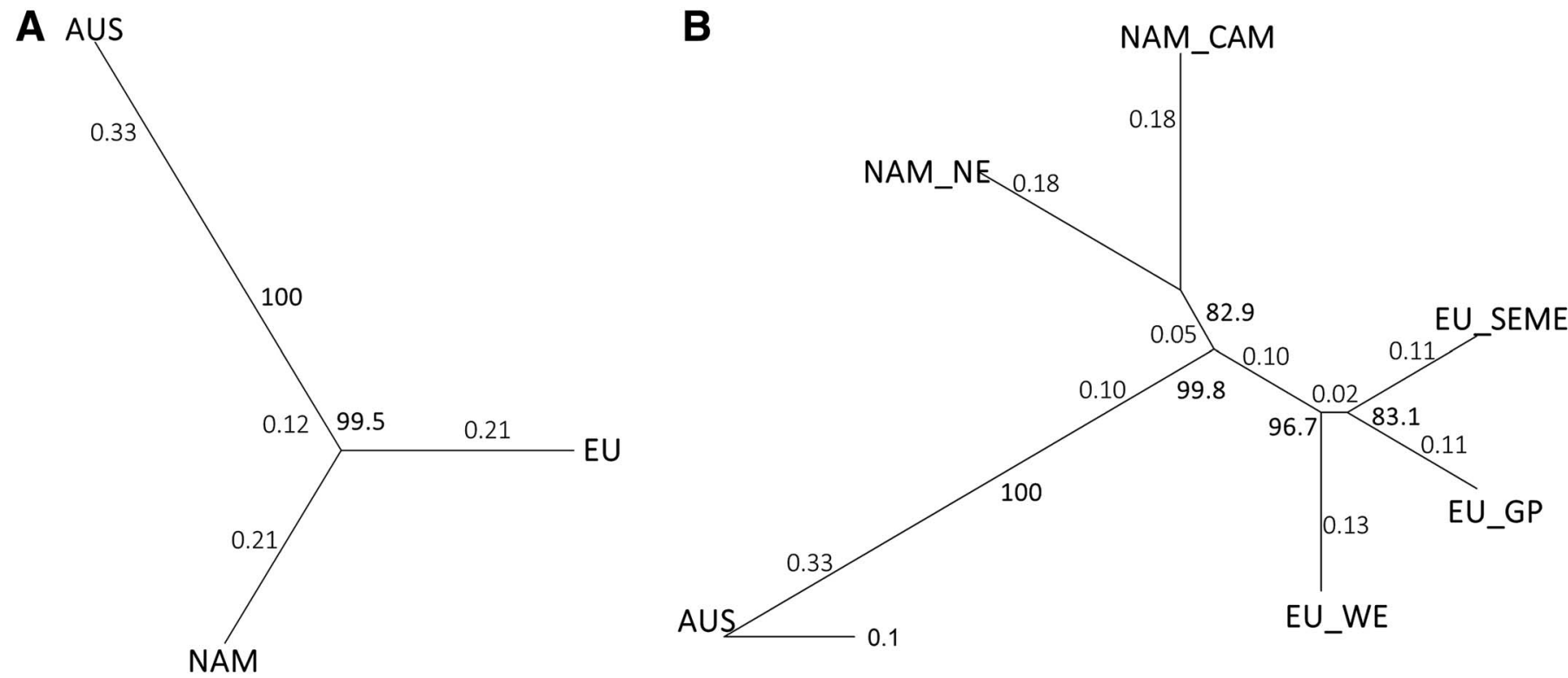

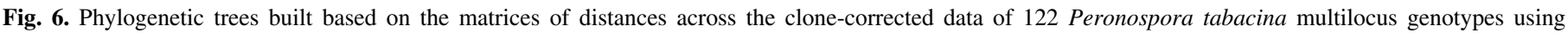

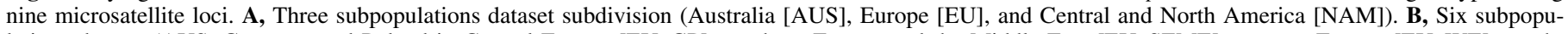

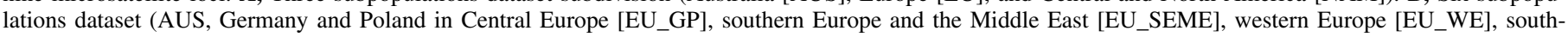

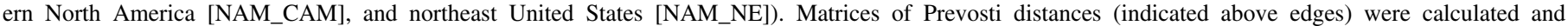
reticulated using poppr in R; bootstrap values $>70 \%$ (indicated at splits in bold) are based on 1,000 permutations of the dataset. 
(Francis et al. 1990; Goodwin et al. 1992; Haas et al. 2009), genetic variation is expected to be high; however, previous studies did not find this (Edreva et al. 1998; Sukno et al. 2002). An alternative explanation of a population bottleneck and the emergence of isolates from a small number of individuals or migration and/or introduction to new geographical areas was provided by Sukno et al. (2002). Our data did not confirm their results even though our collection of this obligate pathogen is the largest studied.

Our study and related P. tabacina studies (Blanco-Meneses et al. 2018) have demonstrated genetic diversity and geographic substructuring among the subpopulations of $P$. tabacina. We also found a significant correlation between geographic and genetic distances, which would be expected if the epidemic had a single origin (Kamvar et al. 2015). Incorporation of the sample age into the Mantel test improved the correlation result only slightly, despite the vast ranges of space and time (111 years) covered. This is in agreement with the calculated SSR mutation rate for P. tabacina being in the midrange for these markers (Stewart et al. 2014) and in agreement with one of the first rates calculated for oomycetes Plasmopara viticola $\left(2.85 \times 10^{-4}\right)$ (Fontaine et al. 2013), Pseudoperonospora cubensis $\left(1.2 \times 10^{-4}\right)$, P. humuli $\left(1.2 \times 10^{-4}\right)$ (Nowicki et al. 2021), and Phytophthora capsici $\left(4.7 \times 10^{-2}\right)$ (Dunn et al. 2014). Furthermore, with the introduction of tobacco to Europe by Columbus in 1492 (Randall 1999), and considering our DIYABC inferences, the upper bound of pathogen replication is $\sim 19$ generations per year.

The genetic diversity data support the contention that the blue mold epidemics are typically not incited by the oospores overwintering in temperate tobacco-growing regions. Instead, they are initiated by the sporangia carried by wind currents from southern subtropical regions in the Americas and the Middle East, where the pathogen is active all year (Aylor 1986; LaMondia and Aylor 2001). Furthermore, the finding of high genetic diversity reflects the history of the spread of $P$. tabacina via infected plant materials from the Americas as a point of origin to Europe and subsequently, to the Middle East, and it agrees with historical records and the inferred origin of the genus Nicotiana (Blanco-Meneses et al. 2018). P. tabacina can be spread rather quickly by asymptomatic infected transplants within regions or by the long-distance dispersal from a uniform source (Klinkowski 1961, 1962; Moss and Main 1988), which can explain the intensive gene flow we observed. Because of the difficulties working with the obligate pathogens and, consequently, a limited number of isolates used during our study, further research is necessary to determine global movement patterns of $P$. tabacina. Additional studies are necessary to reveal the geographic identity of the "ghost" subpopulations of $P$. tabacina and how the Australian subpopulation fits into our inferred scenario (i.e., whether the initial inoculum had been brought from Australia to the Americas or vice versa).

Conclusions. This study underscores the evolutionary past and potential of $P$. tabacina, a blue mold pathogen of tobacco. Using SSRs and the global collection of this obligate biotroph, our analyses pointed to Australia as the species' origin, with subsequent intensive migration shaping the extant population structure and species diversity. Tobacco is a versatile crop plant. Because of the ongoing selective pressure on the pathogen by intensive spray programs, $P$. tabacina-related problems are expected to worsen in the future. However, limitations of shipments of plant materials and diversified plant protection programs are viable methods of limiting the ensuing losses.

\section{ACKNOWLEDGMENTS}

We thank the University of Tennessee Institute of Agriculture for support and the following herbaria for samples used for destructive testing during this study: Queensland Plant Pathology Herbarium, Brisbane (Australia); New South Wales Plant Pathology and Mycology Herbarium, New South Wales (Australia); and Universität Hohenheim Herbarium, Stuttgart-Hohenheim (Germany). The use of any trade names is for identification purposes only and does not imply their endorsement by the authors or the study funding entities. The funding agency had no role in study design, data collection and analysis, decision to publish, or preparation of the manuscript.

\section{LITERATURE CITED}

Agapow, P.-M., and Burt, A. 2001. Indices of multilocus linkage disequilibrium. Mol. Ecol. Notes 1:101-102.

Aylor, D. E. 1986. A framework for examining inter-regional aerial transport of fungal spores. Agric. For. Meteorol. 38:263-288.

Aylor, D. E., Taylor, G. S., and Raynor, G. S. 1982. Long-range transport of tobacco blue mold spores. Agric. Meteorol. 27:217-232.

Bailey, F. 1890. Contributions to the Queensland flora. Department of Agriculture Queensland Botany Bulletin. 1:3-7.

Balfour, E. 1887. The Agricultural Pests of India, and of Eastern and Southern Asia, Vegetable and Animal, Injurious to Man and His Products. London, Bernard Quaritch, 15 Piccadilly.

Blanco-Meneses, M. 2010. Population Biology and Detection of the Tobacco Blue Mold Pathogen, Peronospora tabacina. North Carolina State University, Raleigh, NC.

Blanco-Meneses, M., Carbone, I., and Ristaino, J. B. 2018. Population structure and migration of the tobacco blue mold pathogen, Peronospora tabacina, into North America and Europe. Mol. Ecol. 27:737-751.

Bourret, T. B., Choudhury, R. A., Mehl, H. K., Blomquist, C. L., McRoberts, N., and Rizzo, D. M. 2018. Multiple origins of downy mildews and mitonuclear discordance within the paraphyletic genus Phytophthora. PLoS One 13:e0192502

Brown, A., Feldman, M., and Nevo, E. 1980. Multilocus structure of natural populations of Hordeum spontaneum. Genetics 96:523-536.

Bruck, R., Gooding, Jr., G., and Main, C. 1982. Evidence for resistance to metalaxyl in isolates of Peronospora hyoscyami. Plant Dis. 66:44-45.

Carrieri, R., Lahoz, E., Tarantino, P., Cermola, M., and Morra, L. 2017. DNA analysis of a tobacco herbarium specimen reveals the presence of Peronospora tabacina in Italy in 1934. Eur. J. Plant Pathol. 148:219-221.

Clayton, E. E., and Gaine, J. G. 1945. Temperature in relation to development and control of clue mold (Peronospora tabacina) of tobacco. J. Agric. Res. 71:171.

Cornuet, J. M., and Luikart, G. 1996. Description and power analysis of two tests for detecting recent population bottlenecks from allele frequency data. Genetics 144:2001-2014.

Cornuet, J.-M., Pudlo, P., Veyssier, J., Dehne-Garcia, A., Gautier, M., Leblois, R., Marin, J.-M., and Estoup, A. 2014. DIYABC v2. 0: A software to make approximate Bayesian computation inferences about population history using single nucleotide polymorphism, DNA sequence and microsatellite data. Bioinformatics 30:1187-1189.

Dean, D. A., Wadl, P. A., Hadziabdic, D., Wang, X., and Trigiano, R. N. 2013. Analyzing microsatellites using the QIAxcel system. Pages 223-243 in: Microsatellites. S. Kantartzi, ed. Springer, Berlin, Germany.

Derevnina, L., Chin-Wo-Reyes, S., Martin, F., Wood, K., Froenicke, L., Spring, O., and Michelmore, R. 2015. Genome sequence and architecture of the tobacco downy mildew pathogen Peronospora tabacina. Mol. Plant-Microbe Interact. 28:1198-1215.

Dluge, K. L. 2017. Genomic Approaches for, and Characterization of Commercially Important Tobacco Loci. North Carolina State University, Raleigh, NC.

Doyle, J. J., and Doyle, J. L. 1987. A rapid DNA isolation procedure for small quantities of fresh leaf tissue. Phytochem. Bull. 19:11-15.

Dray, S., and Dufour, A.-B. 2007. The ade4 package: Implementing the duality diagram for ecologists. J. Stat. Softw. 22:1-20.

Dunn, A. R., Bruening, S. R., Grünwald, N. J., and Smart, C. D. 2014. Evolution of an experimental population of Phytophthora capsici in the field. Phytopathology 104:1107-1117.

Edreva, A., Delon, R., and Coussirat, J. 1998. Variability of Peronospora tabacina A.-an isoenzyme study. Beiträge zur Tabakforschung/Contributions to Tobacco Research 18:3-13.

Evanno, G., Regnaut, S., and Goudet, J. 2005. Detecting the number of clusters of individuals using the software STRUCTURE: A simulation study. Mol. Ecol. 14:2611-2620.

Farlow, W. G. 1885. Notes on some injurious fungi of California. Bot. Gaz. 10:346-348.

Fontaine, M. C., Austerlitz, F., Giraud, T., Labbé, F., Papura, D., RichardCervera, S., and Delmotte, F. 2013. Genetic signature of a range expansion and leap-frog event after the recent invasion of Europe by the grapevine downy mildew pathogen Plasmopara viticola. Mol. Ecol. 22:2771-2786.

Francis, R. M. 2017. pophelper: An R package and web app to analyze and visualize population structure. Mol. Ecol. Res. 17:27-32.

Francis, D. M., Hulbert, S. H., and Michelmore, R. W. 1990. Genome size and complexity of the obligate fungal pathogen, Bremia lactucae. Exp. Mycol. 14:299-309. 
Gayevskiy, V., Klaere, S., Knight, S., and Goddard, M. R. 2014. ObStruct: A method to objectively analyse factors driving population structure using Bayesian ancestry profiles. PLoS One 9:e85196.

Gobbin, D., Pertot, I., and Gessler, C. 2003. Identification of microsatellite markers for Plasmopara viticola and establishment of high throughput method for SSR analysis. Eur. J. Plant Pathol. 109:153-164.

Goodwin, S., Drenth, A., and Fry, W. 1992. Cloning and genetic analyses of two highly polymorphic, moderately repetitive nuclear DNAs from Phytophthora infestans. Curr. Genet. 22:107-115.

Grünwald, N. J., Goodwin, S. B., Milgroom, M. G., and Fry, W. E. 2003. Analysis of genotypic diversity data for populations of microorganisms. Phytopathology 93:738-746.

Haas, B. J., Kamoun, S., Zody, M. C., Jiang, R. H., Handsaker, R. E., Cano, L. M., Grabherr, M., Kodira, C. D., Raffaele, S., and Torto-Alalibo, T. 2009. Genome sequence and analysis of the Irish potato famine pathogen Phytophthora infestans. Nature 461:393-398.

Hackshaw, A., Morris, J. K., Boniface, S., Tang, J.-L., and Milenković, D. 2018. Low cigarette consumption and risk of coronary heart disease and stroke: meta-analysis of 141 cohort studies in 55 study reports. BMJ 360:5855.

Halkett, F., Simon, J.-C., and Balloux, F. 2005. Tackling the population genetics of clonal and partially clonal organisms. Trends Ecol. Evol. 20: 194-201.

Hardy, O., and Vekemans, X. 2015. SPAGeDi 1.5. A Program for Spatial Pattern Analysis of Genetic Diversity. User's Manual. Université Libre de Bruxelles, Brussels, Belgium. https://ebe.ulb.ac.be/ebe/SPAGeDi_files/ SPAGeDi_1.5 Manual.pdf

Hardy, O. J., and Vekemans, X. 2002. SPAGeDi: A versatile computer program to analyse spatial genetic structure at the individual or population levels. Mol. Ecol. Notes 2:618-620.

Hey, J., Chung, Y., Sethuraman, A., Lachance, J., Tishkoff, S., Sousa, V. C., and Wang, Y. 2018. Phylogeny estimation by integration over isolation with migration models. Mol. Biol. Evol. 35:2805-2818.

Hey, J., and Nielsen, R. 2004. Multilocus methods for estimating population sizes, migration rates and divergence time, with applications to the divergence of Drosophila pseudoobscura and D. persimilis. Genetics 167: 747-760.

Hill, A. V., and Mandryk, M. 1962. Resistance of seedlings of Nicotiana species to Peronospora tabacina Adam. Aust. J. Exp. Agric. 2:12-15.

Hubisz, M. J., Falush, D., Stephens, M., and Pritchard, J. K. 2009. Inferring weak population structure with the assistance of sample group information. Mol. Ecol. Resour. 9:1322-1332

Jombart, T. 2008. Adegenet: An R package for the multivariate analysis of genetic markers. Bioinformatics 24:1403-1405.

Jorde, L. B., Bamshad, M., and Rogers, A. R. 1998. Using mitochondrial and nuclear DNA markers to reconstruct human evolution. BioEssays 20: 126-136.

Jost, L. 2008. GST and its relatives do not measure differentiation. Mol. Ecol. 17:4015-4026.

Jost, L., Archer, F., Flanagan, S., Gaggiotti, O., Hoban, S., and Latch, E. 2018. Differentiation measures for conservation genetics. Evol. Appl. 11:1139-1148.

Kamvar, Z., Larsen, M., Kanaskie, A., Hansen, E., and Grünwald, N. 2015. Spatial and temporal analysis of populations of the sudden oak death pathogen in Oregon forests. Phytopathology 105:982-989.

Kamvar, Z. N., Tabima, J. F., and Grunwald, N. J. 2014. Poppr: An R package for genetic analysis of populations with clonal, partially clonal, and/or sexual reproduction. PeerJ 2:e281.

Kanetis, L., Wang, X., Wadl, P., Neufeld, K., Holmes, G., Ojiambo, P., Cubeta, M., and Trigiano, R. 2009. Microsatellite loci from the cucurbit downy mildew pathogen Pseudoperonospora cubensis. Mol. Ecol. Resour. 9:1460-1466.

Klinkowski, M. 1961. Blue mould (Peronospora tabacina Adam). Dtsch Landwirtsch 12:229-239.

Klinkowski, M. 1962. The European pandemics of Peronospora tabacina Adam, the causal agent of blue mould of tobacco. Biol. Zent. B1. 81:75-89.

Korbie, D. J., and Mattick, J. S. 2008. Touchdown PCR for increased specificity and sensitivity in PCR amplification. Nat. Protoc. 3:1452-1456.

Krauthausen, H., Bauerman, W., and Spring, O. 2003. Metalaxyl resistance of Peronospora tabacina in Germany. Nachrbl. Deutscher Pflanzenschutzd. 55:141-144.

LaMondia, J. 2009. Efficacy of fungicides and a systemic acquired resistance activator (acibenzolar-S-methyl) against tobacco blue mould. Crop Prot. 28:72-76.

LaMondia, J. 2010. January temperatures predict tobacco blue mold severity: Evidence for local source and long-distance transport of inoculum in Connecticut. Plant Dis. 94:119-124.

LaMondia, J. 2013. Reduced sensitivity of Peronospora tabacina, causal agent of tobacco blue mold, to dimethomorph fungicide in Connecticut. Tob. Sci. 50:19-24.
LaMondia, J. A., and Aylor, D. E. 2001. Epidemiology and management of a periodically introduced pathogen. Biol. Invasions 3:273-282.

Lucas, G. 1980. The war against blue mold. Science 210:147-153.

Mantooth, K., Hadziabdic, D., Boggess, S. L., Windham, M., Miller, S., Cai, G., Stapafora, J., Zhang, N., Staton, M. E., Onwley, B., and Trigiano, R. N. 2017. Confirmation of independent introductions of an exotic plant pathogen of Cornus species, Discula destructiva, on the east and west coasts of North America. PLoS One 12:e0180345.

Massee, G. 1899. A Text-Book of Plant Diseases Caused by Cryptogamic Parasites. Duckworth and Company, London, United Kingdom.

Matschiner, M., and Salzburger, W. 2009. TANDEM: Integrating automated allele binning into genetics and genomics workflows. Bioinformatics 25: 1982-1983.

Milgroom, M. G. 1996. Recombination and the multilocus structure of fungal populations. Annu. Rev. Phytopathol. 34:457-477.

Milholland, R., Papadopoulou, J., and Daykin, M. 1981. Histopathology of Peronospora tabacina in systemically infected burley tobacco. Phytopathology 71:73-76.

Moss, M., and Main, C. 1988. The effect of temperature on sporulation and viability of isolates of Peronospora tabacina collected in the United States. Phytopathology 78:110-114.

Nei, M. 1972. Genetic distance between populations. Am. Nat. 106:283-292.

Nei, M. 1978. Estimation of average heterozygosity and genetic distance from a small number of individuals. Genetics 89:583-590.

Nowicki, M., Hadziabdic, D., Trigiano, R. N., Boggess, S. L., Kanetis, L., Wadl, P. A., Ojiambo, P. S., Spring, O., Thines, M., Runge, F., and Scheffler, B. E. 2021. 'Jumping Jack': genomic microsatellites underscore the distinctiveness of closely related Pseudoperonospora cubensis and Pseudoperonospora humuli and provide new insights into their evolutionary past. Front. Microbiol. 12:1802.

Ojiambo, P., and Holmes, G. 2011. Spatiotemporal spread of cucurbit downy mildew in the eastern United States. Phytopathology 101:451-461.

Oksanen, J., Blanchet, F. G., Kindt, R., Legendre, P., Minchin, P. R., O'Hara, R., Simpson, G. L., Solymos, P., Stevens, M. H. H., and Wagner, H. 2013. Package 'vegan'. Community ecology package, version 2:1-295. Comprehensive R Archive Network; http://vegan.r-forge.r-project.org/

Patrick, D. L., Cheadle, A., Thompson, D. C., Diehr, P., Koepsell, T., and Kinne, S. 1994. The validity of self-reported smoking: a review and metaanalysis. Am. J. Public Health 84:1086-1093.

Peakall, R., and Smouse, P. E. 2012. GenAlEx 6.5: Genetic analysis in Excel. Population genetic software for teaching and research-an update. Bioinformatics 28:2537-2539.

Perumal, R., Nimmakayala, P., Erattaimuthu, S. R., No, E.-G., Reddy, U. K., Prom, L. K., Odvody, G. N., Luster, D. G., and Magill, C. W. 2008. Simple sequence repeat markers useful for sorghum downy mildew (Peronosclerospora sorghi) and related species. BMC Genet. 9:1-14.

Prevosti, A. 1974. La distancia genética entre poblaciones. Miscellanea Alcobé. Public. Universidad de Barcelona, 109-118.

Pritchard, J. K., Stephens, M., and Donnelly, P. 2000. Inference of population structure using multilocus genotype data. Genetics 155:945-959.

R Core Team. 2019. R: A Language and Environment for Statistical Computing (Version 3.6. 1). R Foundation for Statistical Computing, Vienna, Austria.

Randall, V. R. 1999. History of Tobacco. Boston University Medical Center, Boston, MA.

Ripley, B., Venables, B., Bates, D. M., Hornik, K., Gebhardt, A., Firth, D., and Ripley, M. B. 2013. Package 'mass'. Cran R 538.

Ristaino, J. B., Johnson, A., Blanco-Meneses, M., and Liu, B. 2007. Identification of the tobacco blue mold pathogen, Peronospora tabacina, by polymerase chain reaction. Plant Dis. 91:685-691.

Spring, O., Gomez-Zeledon, J., Hadziabdic, D., Trigiano, R. N., Thines, M., and Lebeda, A. 2018. Biological characteristics and assessment of virulence diversity in pathosystems of economically important biotrophic oomycetes. Crit. Rev. Plant Sci. 37:439-495.

Spring, O., Hammer, T., Zipper, R., and Billenkamp, N. 2013. Population dynamics in tobacco blue mold incidences as a consequence of pathogen control and virulence performance of Peronospora tabacina phenotypes. Crop Prot. 45:76-82.

Spurr, H., and Todd, F. 1982. Oospores in blue mold diseased North Carolina burley and flue-cured tobacco. Tob. Sci. 26:44-46.

Stewart, S., Abeysekara, N., and Robertson, A. E. 2014. Pathotype and genetic shifts in a population of Phytophthora sojae under soybean cultivar rotation. Plant Dis. 98:614-624.

Stoddart, J. A., and Taylor, J. F. 1988. Genotypic diversity: Estimation and prediction in samples. Genetics 118:705-711.

Sukno, S. A., Taylor, A. M., and Farman, M. L. 2002. Genetic uniformity among isolates of Peronospora tabacina, the tobacco blue mold pathogen. Phytopathology 92:1236-1244. 
Tautz, D. 1989. Hypervariabflity of simple sequences as a general source for polymorphic DNA markers. Nucleic Acids Res. 17:6463-6471.

Telle, S., and Thines, M. 2008. Amplification of cox2 ( $620 \mathrm{bp})$ from $2 \mathrm{mg}$ of up to 129 years old herbarium specimens, comparing 19 extraction methods and 15 polymerases. PLoS One 3:e3584.

Thines, M., and Choi, Y.-J. 2016. Evolution, diversity, and taxonomy of the Peronosporaceae, with focus on the genus Peronospora. Phytopathology 106:6-18.

Tommerup, I. C. 1989. Nuclear behaviour during conidial ontogeny of Bremia lactucae. Mycol. Res. 92:61-68.

Trigiano, R., and Spurr, Jr., H. 1987. The development of the multinucleate condition of Peronospora tabacina sporangia. Mycologia 79:353-357.

Trigiano, R. N., Wadl, P. A., Dean, D., Hadziabdic, D., Scheffler, B. E., Runge, F., Telle, S., Thines, M., Ristaino, J., and Spring, O. 2012. Ten polymorphic microsatellite loci identified from a small insert genomic library for Peronospora tabacina. Mycologia 104:633-640.

Wickham, H. 2011. ggplot2. Wiley Interdiscip. Rev. Comput. Stat. 3:180185.

Wolf, F., McLean, R., and Dixon, L. 1936. Further studies on downy mildew of tobacco. Phytopathology 26:760-777.

Wu, X., Li, D., Bao, Y., Zaitlin, D., Miller, R., and Yang, S. 2015. Genetic dissection of disease resistance to the blue mold pathogen, Peronospora tabacina, in tobacco. Agronomy (Basel) 5:555-568.

Zipper, R., Hammer, T. R., and Spring, O. 2009. PCR-based monitoring of recent isolates of tobacco blue mold from Europe reveals the presence of two genetically distinct phenotypes differing in fungicide sensitivity. Eur. J. Plant Pathol. 123:367-375. 